San Jose State University

SJSU ScholarWorks

Master's Theses

Master's Theses and Graduate Research

1992

\title{
Taxon-specific analysis of microzooplankton grazing rates and phytoplankton growth rates estimated from chromatographic pigment analysis
}

Tye Y. Waterhouse

San Jose State University

Follow this and additional works at: https://scholarworks.sjsu.edu/etd_theses

\section{Recommended Citation}

Waterhouse, Tye Y., "Taxon-specific analysis of microzooplankton grazing rates and phytoplankton growth rates estimated from chromatographic pigment analysis" (1992). Master's Theses. 433.

DOI: https://doi.org/10.31979/etd.nwb6-tcrz

https://scholarworks.sjsu.edu/etd_theses/433

This Thesis is brought to you for free and open access by the Master's Theses and Graduate Research at SJSU ScholarWorks. It has been accepted for inclusion in Master's Theses by an authorized administrator of SJSU ScholarWorks. For more information, please contact scholarworks@sjsu.edu. 


\section{INFORMATION TO USERS}

This manuscript has been reproduced from the microfilm master. UMI films the text directly from the original or copy submitted. Thus, some thesis and dissertation copies are in typewriter face, while others may be from any type of computer printer.

The quality of this reproduction is dependent upon the quality of the copy submitted. Broken or indistinct print, colored or poor quality illustrations and photographs, print bleedthrough, substandard margins, and improper alignment can adversely affect reproduction.

In the unlikely event that the author did not send UMI a complete manuscript and there are missing pages, these will be noted. Also, if unauthorized copyright material had to be removed, a note will indicate the deletion.

Oversize materials (e.g., maps, drawings, charts) are reproduced by sectioning the original, beginning at the upper left-hand corner and continuing from left to right in equal sections with small overlaps. Each original is also photographed in one exposure and is included in reduced form at the back of the book.

Photographs included in the original manuscript have been reproduced xerographically in this copy. Higher quality $6^{\prime \prime} \times 9^{\prime \prime}$ black and white photographic prints are available for any photographs or illustrations appearing in this copy for an additional charge. Contact UMI directly to order.

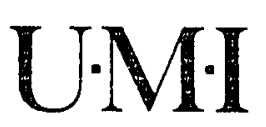

University Microfilms Internatıonal

A Bell \& Howelt intormation Company

300 North Zeeb Road. Ann Arbor. M1 48106-1346 USA

$313: 761-4700 \quad 800: 521.0600$ 
Order Number 1350127

Taxon-specific analysis of microzooplankton grazing rates and phytoplankton growth rates estimated from chromatographic pigment analysis

Waterhouse, Tye York, M.S.

San Jose State University, 1992

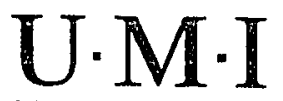

300 N. Zeeb Rd.

Ann Arbor, MI 48106 


\title{
TAXON-SPECIFIC ANALYSIS OF MICROZOOPLANKTON GRAZING RATES AND PHYTOPLANKTON GROWTH RATES ESTIMATED FROM CHROMATOGRAPHIC PIGMENT ANALYSIS
}

\author{
A Thesis \\ Presented to \\ The Faculty of Moss Landing Marine Laboratories \\ San Jose State University
}

\author{
In Partial Fulfillment \\ of the Requirements for the Degree \\ Master of Science \\ in \\ Marine Science
}

By

Tye Y. Waterhouse

August, 1992 
APPROVED FOR MOSS LANDING MARINE LABORATORIES

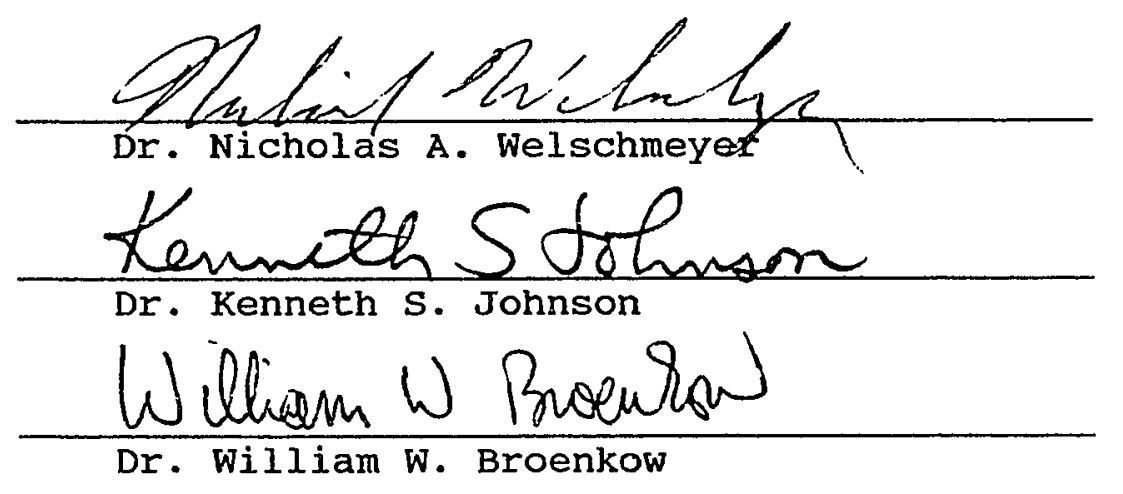

APPROVED FOR THE UNIVERSITY

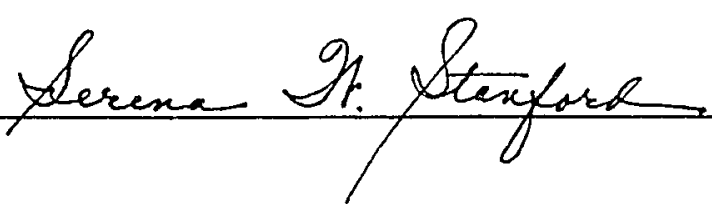




\begin{abstract}
TAXON-SPECIFIC ANALYSIS OF MICROZOOPLANKTON GRAZING RATES AND PHYTOPLANKTON GROWTH RATES ESTIMATED FROM CHROMATOGRAPHIC PIGMENT ANALYSIS
\end{abstract}

by Tye $Y$. Waterhouse

Laboratory experiments were performed to test the accuracy of taxon-specific grazing and growth rates obtained by the dilution technique with HPLC. Field experiments were conducted to obtain taxon-specific estimates of microzooplankton grazing and phytoplankton growth rates in Monterey Bay, California. Seven of the nine laboratory experiments underestimated microzooplankton grazing rates. The average ratios of observed grazing rates:true grazing rates from chlorophyll a were 0.52 , and 0.33 for taxonspecific pigments. Clearance rates for oxyrrhis marina were between $2 * 10^{-3}$ and $7 * 10^{-3} \mathrm{ml} \operatorname{grazer}^{-1}$ day ${ }^{-1}$, at initial food concentrations of approximately $5 * 10^{3}$ cells $\mathrm{ml}^{-1}$. At higher food concentrations $\left(1 * 10^{5}\right.$ cells $\left.\mathrm{ml}^{-1}\right)$ clearance rates decreased to approximately $1 * 10^{-4} \mathrm{ml}$ grazer $^{-1} \mathrm{day}^{-1}$. Field experiments performed in September 1991, and March 1992, showed that a significant fraction (21-55\%) of the phytoplankton standing stock was consumed daily by microzooplankton grazing. The laboratory experiments suggests that microzooplankton grazing rates obtained from the field may also be underestimates. 


\section{ACKNOWLEDGEMENTS}

The completion of this project could not have been possible without the help of many people. I am very grateful for the help and guidance I received from my major advisor

Dr. Nicholas Welschmeyer. I also want to extend my thanks to my other committee members Dr. Kenneth Johnson and Dr. William Broenkow.

I would also like to thank the Dr. Earl Myers and Ethel Myers oceanographic and marine biology trust for financial assistance. 
TABLE OF CONTENTS

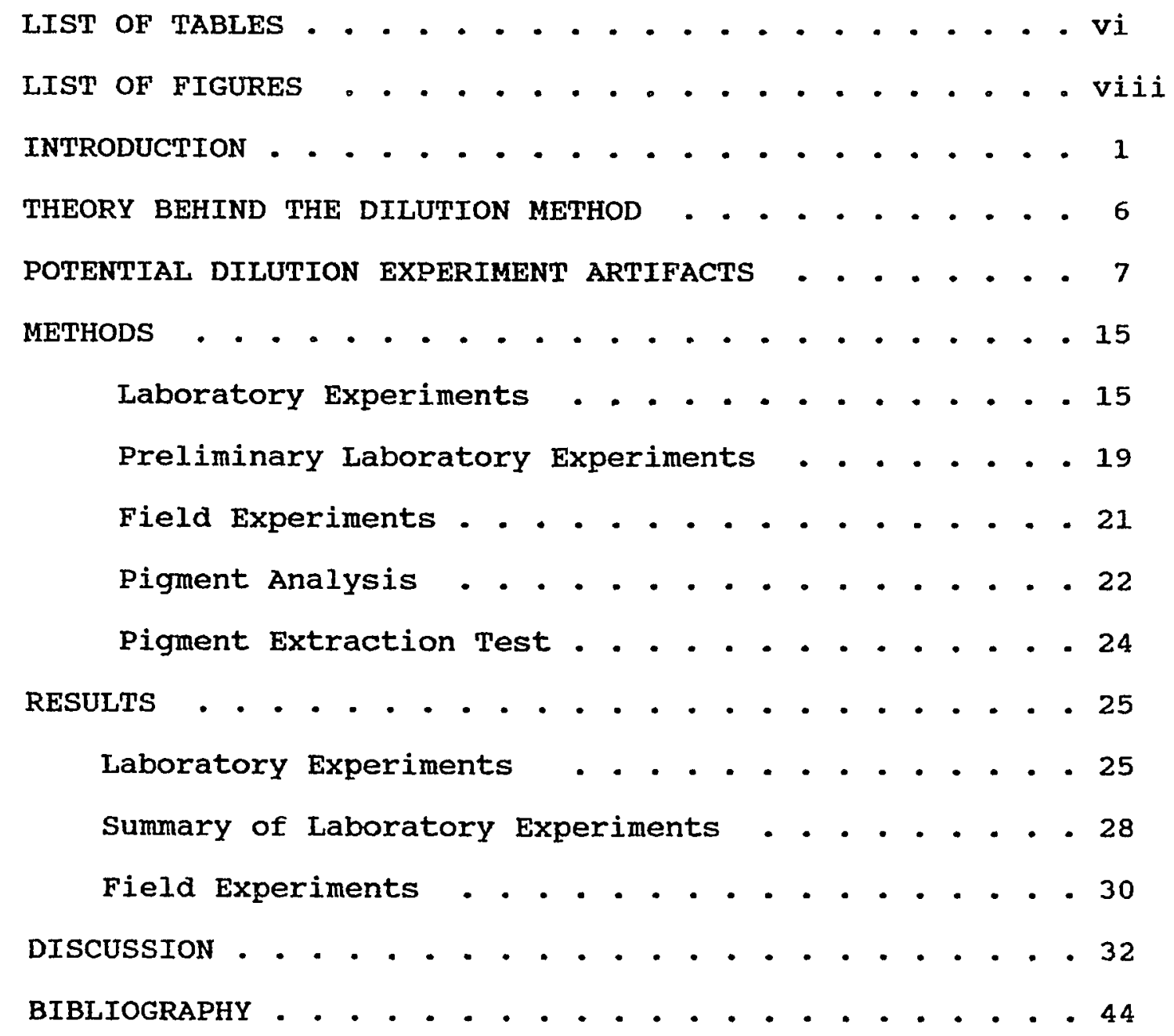




\section{LIST OF TABLES}

Table

Page

1. Chlorophyll and major carotenoid pigments among classes of phytoplankton. $\mathrm{DD}=$ diadinoxanthin, DT=diatoxanthin, V=violaxanthin, $A=$ antheraxanthin, $\mathrm{Z}=$ zeaxanthin . 48

2. Possible dilution experiment errors, and the results of such errors on the calculated microzooplankton grazing rates and phytoplankton growth rates . . . . . . . . . 48

3. Solvent gradient used to separate pigments. Solvent $A=85 \%$ methanol $15 \%$ ammonium acetate,

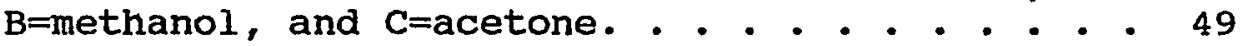

4. The peak areas of major pigments from four food sources extracted by soaking and grinding. 19'hex $=19^{\prime}$-hexanoyloxyfucoxanthin . . . . . . 49

5. The true grazing $(g)$ and growth $(u)$ rates $\left(d^{-1}\right)$ obtained from cell counts and, grazing and growth rates (with $95 \%$ confidence intervals) from dilution plots provided by each pigment in the three laboratory experiments with Gymnodinium sp. which contained peridinin. The grazing rate is obtained from the negative slope of the dilution plot. However, some plots showed a slightly positive slope. The results provided by these plots are in parentheses. Chl a=chlorophyll a, Chl $c=$ chlorophyll $c$, Peri=peridinin, $\mathrm{DD}=$ diadinoxanthin, B-car=beta-carotene. . . . 50

6. The ratio of observed grazing rates:true grazing rates provided by each pigment in the nine laboratory experiments. Samples with slight positive slopes in parentheses were considered to have slopes of zero. $19^{\prime}$ hexanoyloxyfucoxanthin (*), Chlorophyll $\mathbf{c}_{3}$ (+). ChI a=chlorophyll a, chl $c=c h l o r o p h y l l ~ c$, Fuco=fucoxanthin, Peri=peridinin, $\mathrm{DD}=$ diadinoxanthin, $\mathrm{B}$-car=beta-carotene . . . 50 
7. The true grazing $(g)$ and growth $(u)$ rates $\left(d^{-1}\right)$ obtained from cell counts and, grazing and growth rates (95\% confidence intervals) from dilution plots provided by each pigment in the six laboratory experiments using Emiliania huxleyi which contains $19^{\prime}$ hexanoyloxyfucoxanthin and phaeodactylum tricornutum and Isochrysis galbana which both contain fucoxanthin. 19'hexanoyloxyfucoxanthin $(*)$, Chlorophyll $c_{3}(+)$. Chl a=chlorophyll a, Chl c=chlorophyll c, Fuco=fucoxanthin, $\mathrm{DD}=$ diadinoxanthin, $\mathrm{B}$-car=beta-carotene. Not determined=nd. . . . . . . . . . . ......

8. Phytoplankton growth and microzooplankton grazing rates (with $95 \%$ confidence intervals) determined for specific pigments for experiments performed at depths of 0,10 , and $20 \mathrm{~m}$ in September 1991 in Monterey Bay, California. Coefficients of determination $\left(r^{2}\right)$ for all regressions are given. Not Determined=nd. $19^{\prime}-\mathrm{But}=19^{\prime}-$ Butanoyloxyfucoxanthin . . . . . . . . . .

9. Phytoplankton growth and microzooplankton grazing rates (with $95 \%$ confidence intervals) determined for specific pigments for experiments performed at depths of 20 and $35 \mathrm{~m}$ in March 1992 in Monterey Bay, California. Coefficients of determination $\left(r^{2}\right)$ for all regressions are given. 19'-Hex $=19^{\prime}-$ Hexanoyloxyfucoxanthin, 19'-But $=19^{\prime}-$ Butanoyloxy fucoxanthin . . . . . . . . .

10. Summary of previous microzooplankton community grazing pressures reported for various regions. Grazing pressure is the percent of the standing stock grazed daily . . . . . . . . . . . . . 54

11. Clearance rates ( $\mathrm{ml} \operatorname{grazer}^{-1} \mathrm{day}^{-1}$ ) obtained for oxyrrhis marina, under initial food concentrations of $1 * 10^{6}$ and $1 * 10^{3}$ cells $\mathrm{ml}^{-1}$, using the food sources phaeodactylum tricornutum, Isochrysis galbana, Rhodomonas sp., Gymnodinium sp., and Emiliania huxleyi. . . 54 


\section{LIST OF FIGURES}

Figure

Page

1. The ideal dilution model (A) and the dilution model under nutrient limitation showing an exaggerated slope and increased phytoplaniton growth rate ( $k$, redrawn from Gifford 1988) • . . 55

2. Generalized functional response curves recognized in predator-prey dynamics. Points P1 and p2 were used as initial prey densities for generating curves in Figure 3... . . . . . . 56

3. Curves of net growth rate versus fraction unfiltered seawater generated using functional response curves shown in Figure 2. (A) initial prey density $=\mathrm{P1}$; (B) initial prey density $=$ P2 . . . . . . . . . . . . . . . .

4. Net growth rate versus fraction unfiltered seawater using three different initial phytoplankton concentrations. A low initial value leads to an overestimation of net growth whereas a high initial value leads to an underestimation of net growth. . . . . . . . 58

5. Clearance rates ( $\mathrm{ml} \operatorname{grazer}^{-1} \mathrm{day}^{-1}$ ) versus fraction unfiltered seawater showing increasing clearance rates with dilution. The initial food concentration for this dilution experiment was approximately $2 * 10^{4}$ cells $\mathrm{ml}^{-1}$. .58

6. Clearance rates ( $F, \mathrm{ml} \operatorname{grazer}^{-1} \mathrm{day}^{-1}$ ) versus food concentration (celis $\mathrm{ml}^{-1}$ ) showing a decrease in apparent clearance rate with increasing food concentration (Frost 1972) . . . 59

7. Clearance rates ( $\mathrm{ml}$ grazer $^{-1} \mathrm{day}^{-1}$ ) versus food biovolume. (A) shows decreasing clearance rates with increasing biovolume and (B) shows fairly constant clearance rates between biovolumes of approximately $10 * 10^{4}$ to $175 * 10^{4} . .60$ 
8. (A) Chromatogram from a laboratory experiment with Gymnodinium sp. (B) chromatogram from a field experiment at the surface in Monterey Bay. $1=$ chl c, $2=$ peridinin, $3=19^{\prime}-$ butanoyloxyfucoxanthin, $4=$ fucoxanthin, $5=19^{\prime}-$ hexanoyloxyfucoxanthin, 6=diadinoxanthin, $7=$ diatoxanthin, $8=$ zeaxanthin, $9=\operatorname{chl} b, 10=\mathrm{ch} 1$ a, 11=beta-carotene. . . . . . . . . . . .

9. Dilution plots (net growth rate versus dilution factor) for pigments analyzed in experiment \#1 with Gymnodinium sp. as the food source. Empty squares represent data points which were not included in the linear regression. Linear regression data are shown. . . . . . . . .

10. Dilution plots (net growth rate versus dilution factor) for pigments analyzed in experiment \#2 with Gymnodinium sp. as the food source. Empty squares represent data points which were not included in the linear regression. Linear regression data are shown. . . . . . . . .

11. Dilution plots (net growth rate versus dilution factor) for pigments analyzed in experiment \#3 with Gymnodinium sp. as the food source. Linear regression data are shown. . . . . . . . . .

12. Dilution plots (net growth rate versus dilution factor) for pigments analyzed in experiment \#4 with Isochrysis galbana as the food source. Empty squares represent data points which were not included in the linear regression. Linear regression data are shown. . . . . . . . . .

13. Dilution plots (net growth rate versus dilution factor) for pigments analyzed in experiment \#5 with Isochrysis galbana as the food source. Empty squares represent data points which were not included in the linear regression. Iinear regression data are shown. . . . . . . . . .

14. Dilution plots (net growth rate versus dilution factor) for pigments analyzed in experiment \#6 with Isochrysis galbana as the food source. Linear regression data are shown . . . . . . 
15. Dilution plots (net growth rate versus dilution factor) for pigments analyzed in experiment \#7 with Phaeodactylum tricornutum as the food source. Linear regression data are shown . . . 68

16. Dilution plots (net growth rate versus dilution factor) for pigments analyzed in experiment \#8 with Emiliania huxleyi as the food source. Empty squares represent data points which were not included in the linear regression. Linear regression data are shown. . . . . . . . . .

17. Dilution plots (net growth rate versus dilution factor) for pigments analyzed in experiment \#9 with Emiliania huxleyi as the food source. Empty squares represent data points which were not included in the linear regression. Linear regression data are shown. . . . . . . . . .

18. Dilution plots (net growth rate versus dilution factor) for pigments analyzed at 0 meters from Monterey Bay in September, 1991. Linear regression data and coefficients of determination $\left(r^{2}\right)$ are shown . . . . . . . .

19. Dilution plots (net growth rate versus dilution factor) for pigments analyzed at 10 meters from Monterey Bay in September, 1991. Linear regression data and coefficients of determination $\left(\mathrm{r}^{2}\right)$ are shown . . . . . . . .

20. Dilution plots (net growth rate versus dilution factor) for pigments anaiyzed at 20 meters from Monterey Bay in September, 1991. Empty squares represent data which was not included in the linear regression. Linear regression data and coefficients of determination $\left(r^{2}\right)$ are shown..

21. Dilution plots (net growth rate versus dilution factor) for pigments analyzed at 20 meters from Monterey Bay in March, 1992. Linear regression data and coefficients of determination $\left(x^{2}\right)$ are shown. . . . . . . . . . . . . . . . .

22. Dilution plots (net growth rate versus dilution factor) for pigments analyzed at 35 meters from Monterey Bay in March, 1992. Linear regression data and coefficients of determination $\left(r^{2}\right)$ are shown. . . . . . . . . . . . . . . . 
$\begin{array}{ll}\text { Figure } & \text { Page }\end{array}$

23. Growth rates versus Grazing rates for pigments analyzed in dilution experiments from Monterey Bay at 0, 10, and 20 meters in September, 1991. Solid line represents steady state where growth = grazing.................... 76

24. Growth rates versus Grazing rates for pigments analyzed in dilution experiments from Monterey Bay at 20 and 35 meters in March, 1992. Solid line represents steady state where growth $=$ grazing. . . . ............... 77 


\section{INTRODUCTION}

Heinbokel (1978) defines microzooplankton as those heterotrophic organisms which pass through a $200 \mathrm{um}$ aperture although other definitions are also accepted. Microzooplankton are individually inconspicuous, rarely dominate zooplankton biomass, and, consequently, receive less attention than larger zooplankton (Landry and Hassett 1982). By virtue of their small size, microzooplankton have disproportionately high specific growth rates and metabolic rates (Heinbokel 1978) and the ability to utilize food resources of a size largely unavailable to the larger crustacean grazers (Heinbokel 1978; Frost 1980). This gives microzooplankton the potential to profoundly influence the trophic dynamics of the total planktonic assemblage (Pomeroy, 1974). Although the quantitative importance of the microplankton in the marine food web was proposed around the turn of the last century (Lohmann 1908, cited in Burkhill et al. 1987), because of their small size, determining their role in the marine environment through experimental techniques has been difficult.

In an effort to determine the importance of microzooplankton as grazers on phytoplankton, past grazing estimates were obtained through indirect calculations. Beers and Stewart (1971) calculated grazing rates from energetic requirements based on size. Heinbokel (1978) presented clearance rates and ingestion rates of cultured 
and natural tintinnids derived from the disappearance of cultured phytoplankton and a starch ingestion technique. Capriulo and Carpenter (1980) employed a more direct technique by dividing a natural assemblage of plankton into two size components. One component, which was passed through a 35 um screen, was assumed to contain mostly phytoplankton, but few microzooplankton, and served as the control, whereas the other component, which passed through a 202 um screen, contained both phytoplankton and microzooplankton. Grazing rates were measured, relative to the control, in the small and large size fractions. One drawback of this technique is that it measures only the grazing impact of microzooplankton which can be retained by a 35 um screen. The results of these experiments provided microzooplankton grazing rates within the same range of values of those found today. For example, Capriulo and Carpenter (1980) estimated that microzooplankton may remove up to $41 \%$ of the phytoplankton stanaing stock. However, these early stuãies estimated microzooplankton community grazing rates, or the grazing rates of a major component of the community, through theoretical calculations or laboratory experiments. Thus, one could only speculate on the actual microzooplankton community grazing rate in the field based on these types of data.

Realizing the importance for a less ambiguous determination of grazing rates of microzooplankters in the marine food web, Landry and Hassett (1982) introduced the 
dilution method for estimating phytoplankton growth rates and microzooplankton grazing rates from natural communities. The technique has been used frequently (Landry et al. 1984, Burkhill 1987, Paranjape 1987, Gifford 1988, Strom and Welschmeyer 1991) and has been analyzed critically by Gallegos (1989, details will be discussed here in a separate section). Burkhill et al. (1987) extended the dilution method with pigment analysis by high pressure liquid chromatography (HPLC). This provides considerably greater discrimination of the trophodynamic interaction between microzooplankton and phytoplankton by allowing estimates of grazing and growth to be made on many chemotaxonomic groups of phytoplankton. This is a potentially powerful tool since the HPLC technique allows the unambiguous measurement, with high analytical sensitivity, of algal chlorophylls and carotenoids, thereby allowing estimates of grazing pressure on each pigment as well as the growth rate of each pigment. Carotenoids such as peridinin (dinoflagellates), alloxanthin (cryptophytes), 19-hexanoyloxyfucoxanthin (haptophytes), and chlorophylls such as chlorophyll b (chlorophytes) and divinyl chlorophyll a (prochlorophytes), for example, are unique among certain groups of phytoplankton and provide a means of identifying different taxonomic groups of phytoplankton in a natural assemblage. Table 1 shows examples of the distribution of chlorophylls and major carotenoid pigments which are directly related to the types of phytoplankton and pigments analyzed in this study (Strom 
and Welschmeyer 1991). However, this technique is limited because it evaluates pigment concentrations, not organism biomass per se. The most direct method would include microscopic enumeration of individual phytoplankton species present in the phytoplankton assemblage, but this would be quite labor intensive.

The dilution method coupled with HPLC pigment analysis offers a unique combination of techniques for the chemotaxonomic determination of phytoplankton growth rates, microzooplankton grazing rates, and microzooplankton grazing preference. However, this method, which assumes that algal pigments are completely degraded after being ingested by a grazer, has not been verified in the laboratory.

There is reason to question the assumption that all pigments can serve as adequate estimates of algal biomass in a dilution experiment. Barlow et al. (1988) and Klein et al. (1986) found that algal chlorophylis and carotenoids were not completely degraded after ingestion by the micrograzer, oxyrrhis marina. They concluded that the use of pigments to track cell biomass would lead to an underestimation of grazing. Barlow et al. (1988) showed that carotenoids and chlorophylls were degraded more slowly than the rate at which phytoplankton cells were ingested. Furthermore, no significant production of chlorophyll breakdown products were observed in particulate matter or in dissolved form. Thus, changes in pigment concentration were not an accurate measure of the cellular grazing rate. Corroborating evidence 
for this was provided by Klein et a1. (1986) who showed that during grazing experiments chlorophylls and carotenoids were degraded to colorless residues. Very little chlorophyll a was degraded to phaeophytin and none to phaeophorbide during grazing. They state that phaeopigment concentrations cannot be used to measure algal mortality due to heterotrophic protozoan grazing. On the other hand, Shuman and Lorenzen (1975) suggested that there is a stoichiometric conversion of chlorophyll to phaeophorbide by zooplankton grazing and thus, chlorophyll a could serve as a reasonable tracer of algal biomass. However, from experiments using copepods, Conover et al. (1986) compared the loss of chlorophyll a with that of an inert tracer, biogenic silica, and found that chlorophyll a and its derivatives could be destroyed or absorbed during passage through the zooplankter's gut. This suggests that the method used by Shuman and Lorenzen (1975) may give misleading results. The objective of this study was to determine, through laboratory experiments, if the dilution method with HPLC pigment analysis provides reliable estimates of growth and grazing, and to provide taxonspecific estimates of microzooplankton grazing rates and phytoplankton growth rates in Monterey Bay, California. 
THEORY BEHIND THE DILUTION NETHOD

The dilution method, introduced by Landry and Hassett (1982), was designed to determine both microzooplankton grazing rates and algal growth rates. Briefly, by making a series of dilutions, using known fractions of natural seawater and filtered seawater, grazing mortality and phytoplankton growth rates can be calculated from observed changes in population density (measured by chlorophyll, cell numbers, taxon specific pigments etc.) following incubation of samples. It is assumed that the population changes according to equation 1 and has the solution shown in equation 2:

$$
\begin{gathered}
d P / d t=k P-g P \\
\ln \left(P_{t} / P_{o}\right) / t=k-g
\end{gathered}
$$

where $P_{o}$ is the initial phytoplankton concentration, $P_{t}$ is the final phytoplankton concentration, $t$ is time, $k$ is the phytoplankton growth rate, and $\mathrm{g}$ is the grazing mortality rate. The observed rate of change of phytoplankton density at the different dilutions is linearly related to the dilution factor (decimal fraction of unfiltered seawater). The negative slope of this relationship is the grazing rate and the $y$-axis intercept is the phytoplankton growth rate. This method requires the following assumptions: 1) The specific growth rate of the phytoplankton must not be altered by dilution, 2) growth of phytoplankton must not be 
limited by available or regenerated nutrients, 3) phytoplankton must be growing at a constant rate and 4) microzooplankton do not exhibit a functional feeding response as a result of changes in prey density (Gallegos 1989). Violating the assumptions of this technique can lead to errors in the calculated rates.

\section{POTENTIAL DILUTION EXPERIMENT ARTIFACTS}

Performing dilution experiments with and without added nutrients, Landry and Hassett (1982) showed that different conclusions about phytoplankton growth rates can be reached depending on the nutrient composition of the medium. In incubations of the natural phytoplankton assemblage, they found that phytoplankton growth rates were lower when nutrients were limiting. In dilution experiments, the limiting nutrient will be depleted more rapidly in the presence of higher densities of phytoplankton. Consequently, the specific growth rate might be low in the relatively undiluted bottles. Thus, under nutrient limitation the relationship between net growth rate and dilution factor may have an exaggerated negative slope (leading to an erroneously high estimate of the microzooplankton grazing rate). Gifford (1988) showed an ideal dilution plot as well as a simulated nutrient limited plot similar to Figure 1. Because of nutrient limitation the relatively undiluted samples have low phytoplankton growth rates. Hence, the slope of the best fit line is exaggerated. This will lead to 
the overestimation of the microzooplankton grazing rate, and may potentially overestimate the phytoplankton growth rate as well. Landry and Hassett (1982) state that with or without added nutrients the actual phytoplankton growth rate is approached when increasingly more dilute samples of the assemblage are incubated. Thus, under conditions of nutrient limitation, true growth rates may be approached by the most diluted samples. As a result, nutrient depletion may only lead to small errors, if anything, in phytoplankton growth rates. Due to the low growth rates in the relatively undiluted samples, however, the microzooplankton grazing rate may be significantly overestimated.

To avoid errors related to nutrient limitation several investigators added nutrients to their experimental bottles before incubation (Landry and Hassett 1982, Paranjape 1987, and Gallegos 1989). However, the addition of nutrients add the concern that growth coefficients may be artificially elevated and will not represent the true in situ growth rates and, some delicate microzooplankton may be poisoned by nutrient additions (Landry and Hassett 1982). Gifford (1988) suggests that the addition of nutrients to the dilution treatment may result in substantial loss of oligotrich ciliates.

On the other hand, Gallegos (1989) states that the close coupling of growth and grazing calculated in his study argues that the overall grazing was not greatly impaired by nutrient addition. In other words, even if certain 
components of the microzooplankton were lost due to nutrient addition, it was not enough to greatly alter the overall community microzooplankton grazing rate. Likewise, Paranjape (1987) adds that in experiments with and without nutrient addition, the negative slopes were not significantly different suggesting that the grazing activity of microzooplankton did not change due to the addition of nutrients. He also adds that phytoplankton did not respond to an increased nutrient supply during a 24 hour incubation. However, significant net growth did occur after 48 hours. Such a lag time is expected for nutrient starved phytoplankton under some conditions (Collos 1986).

Perhaps the assumption most likely to be violated concerns the potential functional feeding response of microzooplankton. Figure 2 shows generalized functional response curves recognized in predator-prey dynamics. The $y-$ axis is the ingestion rate which is the number of prey consumed per grazer per time (prey grazer ${ }^{-1}$ time $^{-1}$ ) and, the $x$-axis is the prey density (prey $\operatorname{vol}^{-1}$ ). Type I shows a linear rise in ingestion rate (constant per capita clearance rates) to a saturation level where ingestion remains constant. At this saturation level the rate of water transport is constant although the prey density is increased. Since the rate of phagocytosis limits the ingestion rate an increased number of trapped prey are lost when food concentration is high. Hence, the apparent per capita clearance rate decreases. The following equation 
describes the relationship between clearance rate and ingestion rate:

$$
C=I / P
$$

where $\mathrm{C}$ is the clearance rate (vol grazer gime $^{-1}$ ), I is the ingestion rate (prey grazer ${ }^{-1} \operatorname{time}^{-1}$ ), and $\mathrm{P}$ is the prey density (prey $\mathrm{vol}^{-1}$ ). At the saturation level, ingestion is constant as prey density increases the resultant clearance rate decreases (equation 3 ). The type I curve is characteristic of animals, mainly suspension feeders, who consume food at a rate proportional to the rate of encounter up to a saturation level. Type II shows a decelerating rise to an asymptotic maximum which is characteristic of most animals which take a certain amount of time to capture and consume their prey. Many insect parasitoids exhibit this type of functional response which is often referred to as the "invertebrate response" (Real 1977). This curve was generated using the Michaelis Menton equation of enzyme kinetics (Real 1977):

$$
f=F * A /(G+\hat{A})
$$

Where $f$ is the ingestion rate (prey grazer grime $^{-1}$ ), F is the maximal ingestion rate (prey $\operatorname{grazex}^{-1} \mathrm{time}^{-1}$ ), $\mathrm{A}$ is the prey density (prey $\mathrm{vol}^{-1}$ ), and $\mathrm{G}$ is an affinity constant (prey $\mathrm{vol}^{-1}$ ) and is equal to the prey density at which the ingestion rate is half-maximal (e.g. $f=F / 2)$. Arbitrary values for each parameter of equation 4 where chosen to 
display the Type II curve in Figure 2. Type III is sigmoidal and indicative of organisms which show a "learning" behavior in which, below a certain threshold food concentration, the organism reduces its feeding effort. This curve was generated using equation 5 (Real 1977):

$$
\mathrm{f}=\mathrm{F} * \mathrm{~A}^{\mathrm{n}} /\left(\mathrm{G}+\mathrm{A}^{\mathrm{n}}\right)
$$

where $f$ is the ingestion rate (prey grazer grime $^{-1}$ ), $F$ is the maximum ingestion rate (prey grazer ${ }^{-1} \operatorname{time}^{-1}$ ), $A$ is the prey density (prey $\mathrm{vol}^{-1}$ ), $\mathrm{G}$ is the prey density (prey $\mathrm{vol}^{-1}$ ) at which the ingestion rate is half-maximal $(f=F / 2)$, and $\mathrm{n}$ is the number of encounters a predator must have with its prey before the predator "learns" to be maximally efficient at feeding on that prey item. As can be seen, equation 4 and equation 5 are closely related. The Type II curve (equation 4) can be thought of as a special case of the Type III curve (equation 5) where the predator is always efficient feeding on the prey item $(n=1)$, whereas in equation 5 the predator must "learn" to be efficient on the prey item through numerous encounters with its prey (Real 1977). The Type IIa curve, presented by Gallegos (1989) is simply a variation of the Type II curve where the predator stops feeding below a threshold food concentration.

Considering the suspension feeder response (Type I), from equation 3 it can be seen that the clearance rate remains constant, as prescribed by the dilution technique, providing the ingestion rate increases linearly with prey 
density over the full dilution series (e.g. ingestion does not become saturated such as the type I curve where prey density is above $P_{1}$ ). Gallegos (1989) shows dilution curves (phytoplankton net growth rates versus dilution factor) for the four feeding response curves in which microzooplankton are either non food-saturated, or food-saturated; similar models are presented here in Figures $3 a$ and $3 b$, respectively. In the non food-saturated example (Figure 3a) net phytoplankton growth rates were calculated from net changes in prey density, using the four functional response curves in Figure 2 (initial prey density equaled P1). In the food-saturated example (Figure 3b) the initial prey density equaled P2. The net phytoplankton growth rates were obtained from the ingestion curves by subtracting the phytoplankton growth rate $\mathrm{k}$ (time ${ }^{-1}$, which was arbitrarily selected and held constant throughout the dilution series) from the microzooplankton grazing rate $g\left(t i m e^{-1}\right)$. The grazing rate was obtained from equation 6:

$$
\mathrm{g}=\mathrm{C} * \mathrm{Z}
$$

where $\mathrm{g}$ is the microzooplankton grazing rate $\left(t_{i m e^{-1}}\right), \mathrm{c}$ is the clearance rate (vol grazer ${ }^{-1} \operatorname{time}^{-1}$ ), and $\mathrm{z}$ is the microzooplankton concentration (grazer vol ${ }^{-1}$ ). The clearance rate (C) was obtained from the ingestion curves (Figure 2) using equation 3. For the simulation plots (Figures $3 a$ and 3b) the initial prey concentration was conveniently selected to equal the initial grazer concentration, and the 
assumption that there was no significant growth of the microzooplankton population over the course of a simulation was made.

In the non food-saturated curve (Figure $3 a$ ) only the Type I curve shows a linear change in net growth rate with dilution factor; all other curves depart from linearity. This occurs because only the Type I curve provides a linear rise in ingestion rate (constant per capita clearance rates) with increasing prey density as assumed by the dilution technique. In figure $3 b$ (food-saturated plot) the net phytoplankton growth rates were calculated as described with the initial prey density equaling P2. In this plot all the feeding responses result in a non-linear relationship between net growth rate and dilution factor. This occurs since none of the functional response curves provide a linear increase in ingestion with increasing prey density (constant per capita clearance rates) when food-saturated. These dilution curves demonstrate the non-linear relationships which can occur from functional feeding responses as a result of diluting the prey. With the exception of the Type I curve in the non food-saturated plot, these curves provide examples of results which may be obtained in the field where the assumption that microzooplankton do not exhibit a functional feeding response may be violated. As Gifford (1988) points out, in cases where feeding thresholds occur at dilute food concentrations microzooplankton grazing rates will be 
overestimated. This occurs as a result of a decrease in grazing at dilute food levels which leads to elevated net phytoplankton growth. Accordingly, the negative slope of the line is exaggerated, resulting in an overestimation of the microzooplankton grazing rate as well as the phytoplankton growth rate. On the other hand, if feeding saturates at high food concentrations, grazing does not decrease linearly with dilution and therefore, the net growth rate does not increase with dilution. Thus, the slope of the line is suppressed which will lead to the underestimation of the microzooplankton grazing rate and the phytoplankton growth rate.

Another potential error in dilution curves may be the overestimation or underestimation of phytoplankton growth rates as a result of an inaccurate measurement of the initial food concentration at the beginning of an experiment. Figure 4 shows simulated dilution curves for three different initial food concentrations (for simplicity, the phytoplankton growth rate for this curve was set at zero). As the result of a low estimate of the initial food concentration, the phytoplankton growth rate was overestimated. A high initial food concentration will underestimate phytoplankton growth. The correct initial value shows zero growth, as expected. From a practical view, the point to note is that an error in the initial food concentration only affects the $\mathrm{Y}$-axis intercept and has no influence on the slope of the line (e.g. the grazing rate). 
Table 2 provides a summary of the sources of dilution experiment errors and the result of such errors on microzooplankton grazing rates and phytoplankton growth rates. All dilution experiments performed in this study were conducted according to the following methods.

\section{KETHODS}

\section{Laboratory Experiments}

Nine laboratory dilution experiments were performed using one of four species of cultured phytoplankton and the micrograzer oxyrrhis marina. Oxyrrhis was chosen because it is easily grown in the laboratory and has been used in grazing experiments by other investigators (Klein et al. 1986, Barlow et al. 1988, Goldman et al. 1989). The food sources were selected on the basis of taxonomic group and size. Oxyrxhis is approximately 20-30 um long and 15-20 um wide (Goldman et al. 1989), and, therefore, all food sources selecteã were less than 20 um in diameter or lengtin. Phytoplankton larger then oxyrrhis did not prove to be suitable food sources.

All experiments were performed according to the following protocol. The phytoplankton species to be used in the laboratory experiments were cultured in Guillard's " $f / 2$ " enriched medium and placed in an incubator at $25^{\circ} \mathrm{C}$. single species of phytoplankton from the exponentially growing stock cultures was added to four 1 of nutrient. enriched filtered seawater collected from Monterey Bay, to 
yield a final concentration of approximately $5000 \mathrm{cells}^{-1} \mathrm{mI}^{-1}$ (approximately 1 ug chlorophyll $1^{-1}$ ), and incubated in the dark at $25^{\circ} \mathrm{C}$ for 48 hours prior to the setup of each experiment. This pretreatment was done to allow the phytoplankton to photoadapt to a dark environment prior to commencement of experimental incubations. The phytoplankton concentrations were selected to avoid changes in feeding behaviors, e.g. the clearance rates of oxyrrhis remained constant in each dilution series as required by the dilution technique. In preliminary experiments where the initial food concentrations used were greater then $2 * 10^{4}$ cells $\mathrm{ml}^{-1}$, constant clearance rates were not maintained (Figure 5, this will be discussed in the next section). This of course, violates the assumption that microzooplankton do not exhibit a functional feeding response. Therefore, all experiments were set up with food concentrations not exceeding $1 * 10^{4}$ cells $\mathrm{ml}^{-1}$. During the setup of each experiment the micrograzer oxyrrhis was added to the phytoplankton culture to yield a grazer concentration of $50-100$ cells $\mathrm{ml}^{-1}$. The grazer concentration was chosen to yield community grazing rates between $0.1 \mathrm{~d}^{-1}$ and $1.0 \mathrm{~d}^{-1}$ which are comparable to the microzooplankton grazing rates previously reported in the natural environment (Landry and Hassett 1982, Burkhill et al. 1987, Paranjape 1987, strom and Welschmeyer 1991). Prior to set-up, oxyrrhis was grown to concentrations of approximately $1 * 10^{4}$ cells $\mathrm{ml}^{-1}$ using the same algal species as was to be used in the experiment. The high concentration 
of oxyrrhis maintained in stock cultures allowed the desired concentration of grazer in each experiment (50-100 cells $\mathrm{ml}^{-1}$ ) to be achieved with a minimal volume of the oxyrrhis concentrate $(20-40 \mathrm{ml})$ and hence minimal algal contamination. To further ensure that phytoplankton were not added along with the grazer, efforts were made to make sure the phytoplankton were completely grazed before the addition of oxyrrhis. This was verified non-quantitatively by visual examination. All initial biomass estimates (cell counts and pigment samples) were taken after dilutions were constructed so that small contributions of algae from the grazer concentrate were accounted for.

Each dilution series was constructed by combining a known volume of the phytoplankton-grazer assemblage with a known volume of filtered seawater to yield the desired dilution. Each dilution mixture was made in a one 1 opaque polypropylene amber bottle. Two amber bottles containing only phytoplankton, which served as controls, were also incubated along with the dilution series to determine the algal growth rate during the course of the experiment. Each dilution series contained eleven bottles, and the dilutions ranged from 1.0 (undiluted) to 0.25 (most dilute). The dilution intervals were chosen to allow a reasonable number of data points for statistical significance, and also allowed constant clearance rates to be maintained in all bottles (this was determined from the examination of clearance rates versus the dilution factor). 
After the dilution series was constructed, the phytoplankton concentration in the control bottles as well as the concentration of phytoplankton and oxyrrhis in the undiluted bottle was determined by cell counts using an epifluorescence microscope (Olympus BH-2, $50 \mathrm{~W}$ mercury light, blue excitation 450-490 nm). Epifluorescence slides were prepared by fixing a subsample from each experimental bottle (30-80 ml) with glutarldehyde (final concentration $2.5 \%)$. Since oxyrrhis does not contain chlorophyll and is therefore very difficult to detect from natural blue-excited fluorescence, cell counts were aided by the use of the nuclear stain 4'6-diamidino-2-phenylindole (DAPI). After approximately 5-10 minutes after glutaraldehyde fixation

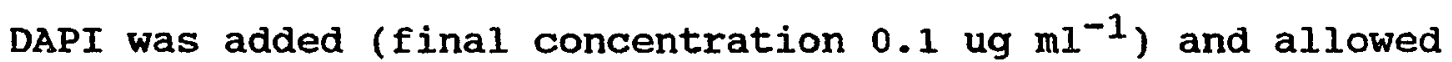
to stain for 5 minutes (Porter and Feig 1980). Each subsample was then gently filtered $(15 \mathrm{~mm} \mathrm{Hg})$ onto a $0.4 \mathrm{um}$ Nuclepore filter until the filter was just dry. The filter was then placed onto a glass slide over a drop of immersion oil (Cargille Type B). Another drop was placed on top of the filter and a glass cover slide was placed on top of that (Booth 1987). Filters were then frozen and stored in the dark for approximately 24 hours before examination. Random fields (10-15) were counted at $200 \mathrm{x}$ magnification. In most cases between 30 and 100 phytoplankton cells and 5-10 Oxyrrhis cells were counted per field.

At the beginning of the experiment, three sub-samples (approximately $150 \mathrm{ml}$ each) were collected from the 
undiluted bottle to obtain initial pigment concentrations for HPLC analysis. Sub-samples were filtered onto whatman GF/F filters which were frozen in liquid nitrogen. The initial phytoplankton and grazer concentrations in each experimental bottle were calculated from the dilution factor. The series was then placed in an incubator at $25^{\circ} \mathrm{C}$ for 48 hours. Incubations were run in the dark to maintain a constant growth rate in all treatments (e.g. zero growth). The dilution technique requires that the phytoplankton growth rates remain constant throughout the dilution series. Although the samples could have been incubated in the light, it is possible that each bottle would not be subjected to identical light intensities when placed in an incubator thereby leading to variable growth rates. After incubation, a subsample $(30-80 \mathrm{ml})$ from each bottle was used to determine the phytoplankton and grazer concentrations based on epifluorescence cell counts. The remaining assemblage in each bottie was filtered volumetricaliy onto a Whatman GF/F filter and frozen for later HPLC analysis.

Preliminary Laboratory Experiments

As discussed, one requirement of the dilution technique is that the clearance rates of the microzooplankton must remain constant in each bottle of the dilution series. Frost (1972) showed a feeding strategy for a mechanical filter feeder in response to increasing food concentrations based on the results of feeding experiments performed with 
the copepod Calanus pacificus (Figure 6). At low food concentrations the clearance rate remains constant. However, at higher food concentrations a saturation level is reached which results in a decrease in the apparent clearance rate. In order to avoid errors in dilution experiments as a result of a functional feeding response, preliminary experiments were conducted to determine a suitable food concentration to use in all laboratory experiments.

In several laboratory experiments, using three different species of phytoplankton and the grazer oxyrrhis, a curve similar to Figure 6 was generated by plotting the concentration (in biovolume $\mathrm{ml}^{-1}$, prey vol * prey concentration) of phytoplankton versus the clearance rate (Figure 7a). At low phytoplankton biomass the clearance rate of oxyrrhis remained constant; however, at higher phytoplankton biomass, clearance rates decreased. Biovolumes between $1 * 10^{5}$ and $175 * 10^{4} \mathrm{um}^{3} \mathrm{ml}^{-1}$ allowed constant ciearance rates to be maintained (Figure 7b). For all phytoplankton species used here this biovolume was achieved by using phytoplankton concentrations between approximately $1 * 10^{3}-9 * 10^{3}$ cells $\mathrm{ml}^{-1}$. As shown in Figure 5 experiments using food concentrations greater than $2 * 10^{4}$ cells $\mathrm{ml}^{-1}$ violated the assumption that microzooplankton do not exhibit a functional feeding response and provided clearance rates which increased as the food concentration was diluted. Thus, the laboratory experiments were designed to eliminate a functional feeding response by the 
microzooplankton.

\section{Field Experiments}

Dilution experiments were conducted in september 1991, and March 1992, at station $\mathrm{H} 3\left(36^{\circ} \mathrm{N}, 122^{\circ} \mathrm{W}\right)$ in Monterey Bay, California, aboard the $R / V$ Point Sur. The procedures of the seawater dilution technique were followed as described by Landry and Hassett (1982). A dilution series consisting of eight bottles was constructed from seawater collected from 0,10 , and $20 \mathrm{~m}$ (September cruise), and 20 and $35 \mathrm{~m}$ (March cruise). Seawater from each depth was collected using 30 1, teflon lined, Go-Flo bottles. Filtered seawater for each dilution series was prepared with a Masterflex peristaltic pump with silicon tubing to pressure-feed seawater through a $4.7 \mathrm{~cm}$ Whatman GF/F filter. Dilution series from each depth were constructed by combining known volumes of natural seawater with filtered seawater (made from seawater collected at the same depth) to obtain the desired dilutions. To eliminate losses of microzooplankton during handling and collection, as reported by Gifford (1985), seawater was slowly drained from the Go-flo bottles through silicon tubing to the bottom of the collection bottle without unnecessary bubbling and harsh handling. Dilutions were carefully made in acid washed milli-Q-rinsed two-l polycarbonate bottles. All bottles were placed in a plexiglass incubator at sunrise, cooled with flowing surface seawater, and allowed to incubate for 24 hours. The series 
from the september experiments at 10 and $20 \mathrm{~m}$ were placed in neutral density screen bags to mimic the ambient light intensity of $16 \%$ and $1 \%$ of the surface irradiation, respectively. The series from the March experiments at 20 and $35 \mathrm{~m}$ were likewise incubated at ambient light intensities of $16 \%$ and $5 \%$ of the surface irradiation.

During set-up, three samples for HPLC analysis were taken from the Go-Flo bottle at each depth for initial pigment measurements. HPLC samples were filtered onto 2.5 $\mathrm{cm}$ Whatman GF/F filters and immediately frozen in liquid nitrogen. Experiments were terminated by filtering a volumetric subsample ( 1 1) of each bottle and freezing the filter for later HPLC analysis ashore.

\section{Pigment Analysis}

Each filter from both laboratory and field experiments were placed in an air tight micro-centrifuge tube, containing $1.2 \mathrm{ml}$ of $90 \%$ acetone, for 24 hours to extract the pigments. After extraction each tube was vortexed on high speed for 30 seconds and, the filters were pressed to the bottom of the tubes with a stainless steel spatula. Each tube was then placed in a Beckman microfuge and spun at high speed for 3 minutes. The pigment extract was diluted with milli-Q water (two parts extract:one part water) just prior to each HPLC injection. Using a solvent gradient, all pigments were removed from the column based on their polarity. The most polar pigments are removed earlier than 
the less polar pigments, thus allowing pigment separation. Pigments were detected by in-line fluorescence and absorbance detectors. To make sure this pigment extraction technique adequately extracted all of the pigment a test was performed to compare this technique with grinding. This test will be discussed in the following section.

Pigment separation was achieved using $85 \%$ methanol:15\% ammonium acetate for solution A, $100 \%$ methanol for solvent B, and $100 \%$ acetone for solvent C (Strom and welschmeyer 1991) through a Microsorb $25 \mathrm{~cm} \mathrm{C}_{18}$ column. The flow rate was $1.5 \mathrm{ml}$ minute ${ }^{-1}$ (gradient listed in Table 3). Peaks were detected by a Kratos FS 950 fluorescence detector and a Linear UVIS 200 absorbance detector set at $440 \mathrm{~nm}$. Peak areas were determined with a Maxima 820 integrator. Calculations of net phytoplankton growth rates, for the dilution plots, were determined using the peak areas from the chromatograms for each pigment. Therefore, it was not necessary for tine HPLC to be calibrated against absolute pigment weights. Figure $8 \mathrm{a}$ and $8 \mathrm{~b}$ show examples of chromatograms from a laboratory experiment and a field experiment respectively. Peaks from chromatograms obtained from field experiments were identified from retention times of peaks derived from "standard" algal cultures. The algal species used as standards were: Gymnodinium sp. (peridinin), Isochrysis galbana (fucoxanthin), Emiliania huxleyi (19'hexanoyloxyfucoxanthin), Dunaliella sp. (violaxanthin), Cryptomonas sp. (alloxanthin), and synechococcus sp. 
(zeaxanthin). Lines fit to dilution plots were by leastsquares linear regression. The $95 \%$ confidence intervals for the grazing (slope) and growth ( $y$-axis intercept) rates were calculated from equations 7 and 8 respectively:

$$
\begin{aligned}
& b \pm t_{0.05} s_{b} \\
& \alpha \pm t_{0.05} s_{\alpha}
\end{aligned}
$$

where $b$ the grazing rate, $\alpha$ is the growth rate, $t_{0.05}$ is the $t$ distribution ( $95 \%$ confidence limit), $s_{b}$ is the standard error of the slope, and $s_{\alpha}$ is the standard error of the $y^{-}$ axis intercept.

Pigment Extraction Test

A $1 \mathrm{ml}$ sample containing a single species of cultured phytoplankton was filtered onto each of six filters. Each filter was placed in an air tight micro-centrifuge tube tube, containing $1.2 \mathrm{ml}$ of $90 \%$ acetone, for 24 hours to allow the pigments to extract. After extraction three of the tubes were vortexed at high speed for 30 seconds and the filters were pressed to the bottom of the tubes with a stainless steel spatula. Each tube was spun in a microcentrifuge at high speed for 3 minutes, diluted, and then processed by HPLC as described earlier. The filters in the remaining three tubes were ground thoroughly with a motordriven tissue grinder, centrifuged, diluted, and then processed by HPLC. This procedure was followed using each of the four phytoplankton species used in the laboratory 
experiments (Gymnodinium sp., Isochrysis galbana, Phaeodactylum tricornutum, and Emiliania huxleyi).

After the samples were processed by HPLC, the mean peak areas of the major pigments, from the four food sources used in the laboratory experiments, obtained by the two extraction techniques were compared. A student's t-test at the $5 \%$ significance level showed that the mean peak areas, for all pigments from the four food sources, obtained from the grinding technique were not significantly different from the mean peak areas obtained from the samples which were not ground. Thus, the pigment extraction technique used was adequate. The peak areas of the major pigments obtained from the two techniques are listed in Table 4.

\section{RESULTS}

\section{Laboratory Experiments}

In all laboratory experiments the true unbiased microzooplankton grazing rate and phytoplankton growth rate was obtained from algal cell counts of the experimental bottles and control bottles, respectively. By constructing a dilution plot using the cell counts from each bottle, the microzooplankton grazing rate (slope) and the phytoplankton growth rate ( $y$-axis intercept) were obtained. These were compared to the grazing and growth rates obtained from the undiluted bottle and the control bottles, respectively, using equation 2. In all experiments the grazing rates. obtained from the dilution plots of cell counts, with $95 \%$ 
confidence intervals, did not significantly differ from the grazing rate calculated from cell counts of the undiluted bottle. Likewise, the growth rates did not differ significantly from zero (cell counts of the control bottles verified a growth rate of zero in all experiments as expected under dark incubation). This suggests that all assumptions associated with the dilution technique must have been met. That is, algal growth rates and per capita grazer clearance rates were constant through each dilution. Therefore, the grazing rate from the dilution plots based on cell counts and a phytoplankton growth rate of zero could be used for comparison with the grazing and growth rates obtained from dilution plots using various pigments. Experiments 1 (Figure 9), 2 (Figure 10), and 3 (Figure 11) were performed using the dinoflagellate Gymnodinium sp. as the food source which contains the taxon-specific pigment peridinin. All pigments in experiment 3 provided growth rates which were not significantly different from zero as would have been expected under experimental dark conditions. Almost all pigments yielded significant underestimates of grazing, including chlorophyll a (Table 5). However, most pigments from experiments 1 and 2 provided growth rates which were significantly less than zero (Table 5). Furthermore, the ratio of observed:true grazing rates for chlorophyll a ranged from 0.00 to 0.48 . The ratio for the taxon-specific pigment peridinin ranged from 0.10 to 0.24 (Table 6). 
Experiments 4 (Figure 12), 5 (Figure 13), and 6 (Figure 14) were performed using the flagellate Isochrysis galbana as the food source which contains the pigment fucoxanthin. All pigments analyzed, except chlorophyll $\mathrm{s}$ in experiment 5, provided significant underestimates of grazing (Table 7). In experiment 5 most pigments did not give growth rates significantly different then zero, whereas almost all pigments from experiments 4 and 6 provided growth rates which were significantly less than zero (Table 7). The ratio of observed:true grazing rates for chlorophyll a from these experiments ranged from 0.34 to 0.59 . In other words, the estimated grazing rates were low by a factor of about 1.53.0. The ratio for fucoxanthin ranged from 0.22 to 0.35 (Table 6). Experiment 7 was performed using the fucoxanthincontaining diatom phaeodactylum tricornutum as the food source. In this experiment all pigments yielded significant underestimates of grazing, and the growth rates were significantly different than zero (Table 7, Figure 15). The ratio of observed:true grazing rates for chlorophyll a and fucoxanthin was 0.48 and 0.31 respectively (Table 6). Experiments 8 (Figure 16) and 9 (Figure 17) were performed using Emiliania huxleyi as the food source which contains the taxon-specific pigment 19'hexanoyloxyfucoxanthin. In both of these experiments all pigments, except 19'-hexanoyloxyfucoxanthin in experiment experiment 8 , provided grazing rates which were not significantly different from the true values (Table 7). All 
pigments in experiment 8 yielded accurate estimates of true growth rate. All pigments in experiment 9, except betacarotene, provided growth rates significantly less than zero (Table 7). The ratio of observed:true grazing rates for chlorophyll a for these experiments ranged from 0.90 to 1.30. The ratio for 19'-hexanoyloxyfucoxanthin ranged from 0.52 to 0.77 (Table 6).

Summary of Laboratory Experiments

Grazing Rates. It is clear from these laboratory experiments that microzooplankton grazing rates were underestimated in most cases. Considering chlorophyll a, all experiments show that, on average, the grazing rates obtained from the dilution plots accounted for $52 \%$ of the true grazing rate (average of all nine experiments). An average of only $33 \%$ of the true grazing rate was achieved when analyzing the carotenoid pigments. Chlorophyll c provided grazing rates approximately $47 \%$ of the true grazing rates. Not all the pigments analyzed from the four food sources underestimated grazing rates, however. Interestingly, the grazing rates from chlorophyll a, chlorophyll $\mathrm{c}$, and beta-carotene from the experiments conducted with the haptophyte Emiliania huxleyi provided accurate estimates of the true grazing rates. The taxonspecific pigment, 19'-hexanoyloxyfucoxanthin, however, provided grazing rates approximately $65 \%$ of the true rate. The carotenoid diadinoxanthin, which was analyzed in most 
experiments presented here, is a photoprotective pigment which undergoes reversible de-epoxidation to form diatoxanthin under high light and, therefore, may be less reliable as biomass indicators then light harvesting pigments (Strom and Welschmeyer 1991).

Most pigments analyzed in experiments 1-7 provide grazing rates which were significantly different from the true grazing rates (Tables 5 and 7). In experiments 8 and 9 , however, most pigments showed excellent agreement between observed and true grazing rates; the only pigment which showed a grazing rate significantly lower from the true value was $19^{\prime}$-hexanoyloxyfucoxanthin in experiment 8 . The portion of the true grazing rate accounted for by the grazing rates were given in Table 6 .

Growth Rates. As can be seen from from the dilution plots, most pigments in experiments $1,2,4,6,7$, and 9 provided phytoplankton growth rates which were significantly less than zero. On the other hand, most pigments from experiments 3,5 , and 8 provided growth rates which were not significantly different from the true value of zero. Examination of the calculated clearance rates in each bottle of a dilution series showed that constant clearance rates were maintained and therefore, a functional feeding response did not occur in these experiments. Thus, the growth estimates which significantly differed from the true value were not a result of a functional feeding response in these 
experiments. If a functional feeding response occurs the dilution curve may demonstrate a non-linear relationship between net growth and dilution factor. This can lead to erroneous grazing rates (slope) as well as phytoplankton growth rates ( $y$-axis intercept). As described in Figure 4 growth rates can be affected by the value of the initial pigment concentration. If the initial concentration is too high then the growth rate can be low. Thus, the inaccurate values of growth could be the result of inadvertently introducing additional pigment to the initial samples through the addition of the micrograzer which contained undegraded pigments. The fact that some experiments provided growth rates which were less then zero and others did not is most likely the result of varying amounts of pigment added at the beginning of each experiment through the grazer. Although the growth rates from the plots which were affected by the addition of initial pigment at time zero are inaccurate, the slope ố the lines (grazing rates) remain unaffected.

\section{Field Experiments}

Field experiments were performed at depths of 0,10 , and $20 \mathrm{~m}$ in September 1991, and 20 and $35 \mathrm{~m}$ in March 1992, at station $\mathrm{H} 3\left(36^{\circ} \mathrm{N}, 122^{\circ} \mathrm{W}\right)$ in Monterey Bay, California. During these cruises, the microzooplankton grazing rates and phytoplankton growth rates obtained at each depth from chlorophyll a ranged from $0.23 \mathrm{~d}^{-1}$ to $0.79 \mathrm{~d}^{-1}$ and $0.53 \mathrm{~d}^{-1}$ 
to $1.30 \mathrm{~d}^{-1}$, respectively (Figures $18-22$ ). The results from september show a close coupling between the community microzooplankton grazing and phytoplankton growth rates at each depth. On average, $69 \%$ of the community phytoplankton growth was balanced by microzooplankton grazing, and 31-55\% of the phytoplankton standing stock was grazed daily. on the other hand, the results from March do not show a close balance between growth and grazing. The average community phytoplankton growth rate which was balanced by grazing was $29 \%$; 21-32\% of the phytoplankton standing stock was grazed daily. Beta-carotene, a precursor pigment for carotenoids which is found in most classes of phytoplankton (LiaaenJensen 1979), like chlorophyll a , potentially serves as a measure of the community microzooplankton grazing rate and phytoplankton growth rate. Beta-carotene also showed a close coupling between grazing and growth at each depth in September $(74 \%$ of growth was balanced by grazing, Figures 18-20). However, in March, only $5 \%$ of beta-carocene growth was balanced by grazing (Figures 21 and 22). Interestingly, the growth rates for zeaxanthin were high during both cruises, however microzooplankton did not preferentially graze on organisms containing zeaxanthin in March as they did in september. In March, it appears as though microzooplankton preferentially grazed on organisms containing $19^{\prime}$-butanoyloxyfucoxanthin $(20 \mathrm{~m})$ and $19^{\prime}-$ butanoyloxyfucoxanthin, 19'-hexanoyloxyfucoxanthin, and alloxanthin $(35 \mathrm{~m})$. The high growth rates obtained from 
zeaxanthin are interesting because they are as much as two times higher then the theoretical maximum growth rate, and they are much higher then the growth rates of zeaxanthin containing phytoplankton reported by other investigators. Tables 8 and 9 (from Figures 18-22) provide a summary of the grazing and growth rates, with $95 \%$ confidence intervals, determined at each depth for specific pigments in september 1991, and March 1992, respectively.

\section{DISCUSSION}

It is currently thought that microzooplankton are a major link in the food web in the open ocean, but in coastal environments they maybe unimportant relative to the conspicuous macrozooplankton communities (Frost 1980, Welschmeyer and Lorenzen 1985). Perhaps investigators stress the importance of microzooplankton in oligotrophic regions because they are consumers of small phytoplankton, and they recycle much needed nutrients. Goldman and caron (1985) state the bulk of nutrient regeneration from microflagellates occurred as direct protozoan excretion. Paasche and Kristiansen (1982) and Andersson et al. (1985) state that the majority of nutrient regeneration is through excretion by microzooplankton. Although microzooplankton may be important grazers in oligotrophic regions, current studies show that microzooplankton are also important grazers in many other regions as well (Landry and Hassett 1982, Landry et al. 1984, Paranjape 1987, Strom and 
Welschmeyer 1991).

Dilution experiments presented here from Monterey Bay show that phytoplankton growth and microzooplankton grazing rates for many pigments analyzed were closely linked. Figures 23 aña 24 are plots of the phytoplankton specific growth rates $\left(d^{-1}\right)$ versus microzooplankton specific grazing rates $\left(\mathrm{d}^{-1}\right)$ for the pigments analyzed in september and March, respectively. In september, almost all of the pigments fall just above the steady state line which shows that although growth and grazing was closely related, the phytoplankton populations were not being decimated. In fact, this curve shows the ability of microzooplankton to keep the algal populations at near steady state regardless of their growth rate. Even though most of the same pigments were present during both studies, in March, most pigments fell well above the steady state line which shows that, for the most part, microzooplankton were not keeping the phytopianition growtin rates in baiance. with the exception of zeaxanthin and beta-carotene, the microzooplankton grazing rates obtained from the two cruises were similar. However, the phytoplankton growth rates for many pigments were higher in March.

Perhaps the most surprising result is the high rates of growth and grazing obtained from zeaxanthin during both studies. Growth rates of zeaxanthin, 3.1-4.5 doublings day d $^{-1}$ in september, and 3.8 doublings day ${ }^{-1}$ at $20 \mathrm{~m}$ in March, were much greater then the maximum growth rate $(2.2$ doublings 
$\mathrm{day}^{-1}$ ) predicted for $15^{\circ} \mathrm{C}$ (Eppley 1972). The presence of zeaxanthin is most likely due to the abundance of Synechococcus spp.. Chlorophytes and prochlorophytes also contain zeaxanthin as well as chlorophyll $\underline{\text { b (Strom and }}$ Welschmeyer 1991). However, the low concentrations of chlorophyll b during these experiments makes their presence unlikely (Figure $8 \mathrm{~b}$ ). The growth rates obtained for zeaxanthin in this study appear high compared to other studies. Landry et al. (1984) report a growth rate of 3 doublings day ${ }^{-1}$ for cyanobacterial populations (such as Synechococcus spp.) in Kaneohe Bay, Hawaii. However, other investigators report lower growth rates for synechococcus spp. in other regions. Campbell and Carpenter (1986) report growth rates of synechococcus spp. in the North Atlantic to average 1.1 doublings day ${ }^{-1}$ and, strom and Welschmeyer (1991) show that growth rates obtained for zearanthin in the North Pacific were between 0.5 and 0.9 doublings day ${ }^{-1}$. The high growth rates of zeaxanthin at the time of this study suggests that unknown environmental factors highly favored the growth of synechococcus and, in september, microzooplankton were able to respond, providing a possible example of a dynamic feedback between predator and prey. Although the mechanisms responsible for the dynamic feedback between predator and prey is unknown (Burkhill et al. 1987), laboratory studies have shown microzooplankton prefer certain size classes of phytoplankton and have the ability to discriminate between different food sources. Gifford 1985 
showed that oligotrichs exhibited maximal growth when fed cultured algae between 2-21 um. Stoecker et al. (1986) found that the ciliate Balanion sp. preferentially feeds on dinoflagellates, which supports its highest rates of growth, when placed in mixtures of microalgae. Stoecker (1988) demonstrated that the ciliate Favella sp. can differentiate between similar sized food sources which differ in nutritional quality. She found that Favella sp. selected live dinoflagellates over similarly sized latex polystyrene microspheres and over Bio-gel P2 polyacrylamide beads. verity (1988) provides evidence that by using chemosensory behavior the planktonic ciliates Tintinnopsis sp. and Strombidium sp. differentiated between food sources based on nutritional quality; both ciliates preferred phytoplankton in exponential growth (low $\mathrm{C}: \mathrm{N}$ ratio) over phytoplankton in stationary growth (high $C: N$ ratio). These studies suggest that microzooplankton have the ability to preferentially graze on selected groups of phytoplankton, as suggested by HPLC-dilution experiments presented here.

The laboratory experiments conducted in this study showed that dilution experiments, analyzed by chlorophyll a, only accounted for an average of $52 \%$ of the true grazing rates. Therefore, approximately $48 \%$ of the chlorophyll a ingested during the experiment remained intact when the experiment was terminated. Carotenoid pigments accounted for only $33 \%$ of the true grazing rates. The grazing rates in these experiments were between approximately 0.1 and 1.0 
day $^{-1}$. Similarly, the grazing rates obtained from all pigments, except zeaxanthin, in the field experiments were also within this range. Considering this, it is reasonable to assume that the grazing rates obtained from Monterey Bay are also underestimates. Thus, it is clear that during these experiments microzooplankton were providing a significant portion of the grazing pressure in Monterey Bay. Zooplankton biomass studies performed in Monterey Bay between July 1974 and June 1977 have shown that, for the most part, the greatest abundance of zooplankton was found between approximately July and October (Silver and Davoll 1975, 1976, 1977). Their data also show periodic increases in zooplankton biomass in the spring (March-May) in 1976 and 1977. Interestingly, the september dilution experiments were conducted during the time when the maximum zooplankton abundance may be expected in the surface waters. Furthermore, the laboratory results presented here suggest that previous dilution experiments performed in other regions are also likely to have underestimated microzooplankton grazing rates. Table 10 provides a summary of community microzooplankton grazing pressures reported for various regions. These reports show that microzooplankton make a considerable contribution to the grazing pressure in many different environments, such as: the oligotrophic region (Landry et al. 1984), coastal areas (Landry and Hassett 1982, Gifford 1988), a subarctic pelagic region (Strom and Welschmeyer 1991), and an arctic region 
(Paranjape 1987). Ali of these results should be considered conservative microzooplankton grazing rates, which makes microzooplankton's significance appear to be much more important then previously expected.

The finding that microzooplankton grazing rates were underestimated in laboratory experiments due to the partial degradation of pigments has been observed previously. Through laboratory feeding experiments using oxyrrhis marina, Barlow et al. (1988) state that the rate of chlorophyll a degradation differed from that of ingestion of whole cells and therefore changes in pigment concentration were not an accurate reflection of cellular grazing rates. This result is supported by klein et al. (1986). These results were verified here through laboratory experiments which show that taxon-specific pigments, as well as common pigments, such as chlorophyll a, can lead to an underestimation of microzooplankton grazing rates obtained by the dilution technique. These results are in partial agreement with experiments performed with larger grazers as well. Nelson (1989) conducted experiments where phytoplankton pigments and their alteration products in macrozooplankton feces were characterized by HPLC. He found that fecal material produced by copepods contained intact phytoplankton carotenoids. When ingested by larger grazers, however, (salps and pelagic crabs) carotenoids were changed to polar carotenoid products. Degradation of chlorophyll a occurred within the guts of both size classes, although some 
intact chlorophyll a was found in all fecal collections. He stated that the difference in carotenoid alterations between the two size classes of grazers may be the result of differences in gut esterases and to the transit time of ingested material through the guts of the animals. Other laboratory experiments have shown that chlorophyll a may be lost by degradation to non-fluorescing phaeopigment derivatives or through absorption within the guts of copepods during grazing. Furthermore, these losses varied between experiments and copepod species suggesting that copepod grazing rates obtained by measuring the changes in pigment concentrations may be unreliable.

Dagg and walser (1987) performed laboratory experiments using the copepod Neocalanus plumchrus where grazing was measured over a wide range of food concentrations. They found that the average chlorophyll a loss in all experiments was only $11 \%$, and they state that there was no tendency for a greater amount of chlorophyll a to be lost at low food concentrations then at high food concentrations. Because of the high pigment recovery rate, they were able to calculate the equivalent amount of chlorophyll a originally ingested from measurements of pigment content in fecal pellets or gut contents. On the other hand, Gieskes et al. (1991) performed laboratory experiments where they measured the degradation of chlorophylls and carotenoids during grazing by the copepod Temora longicornis. After 24 hours they found that between $0 \%$ to $40 \%$ of the ingested chlorophyll a was lost; 
after 70 hours $54 \%$ to $0 \%$ of chlorophyll a was lost. The variability in the amount of chlorophyll a lost in each experiment led them to conclude that grazing pressure cannot be estimated from changes in pigment concentration. Using the copepod Calanus pacificus, Lopez et al. (1988) performed laboratory grazing experiments to measure the destruction of chlorophyll a. They found that the fraction of chlorophyll a lost during grazing can be both high and variable. For example, they report chlorophyll a losses during grazing to be between $0 \%$ to $92 \%$. They suggest that the loss of chlorophyll a is due its destruction to non-fluorescing phaeopigment derivatives during grazing. They conclude that using only chlorophyll a and phaeopigments as tracers of ingested phytoplankton can underestimate grazing pressure by an unknown extent. Head (1988, cited in Lopez et al. 1988) reported chlorophyll a losses between $16 \%$ and $54 \%$ from grazing experiments with the copepod Pseudocalanus.

Conover et aI. (1986) report that grazing experiments, where the copepod calanus spp. was feeding at a low rate, resulted in high digestive efficiency with pigment losses of 90-99\%. In other words, almost all of the pigment ingested was destroyed by digestion in the copepods' guts. Wang and Conover (1986) conducted experiments to compare the ingestion rates of the copepod Temora longicornis obtained from gut pigment information with actual filtration rate measurements. They found a discrepancy between the two at low ingestion rates which was due to chlorophyll degradation 
or absorption within the gut of the copepod. Thus, pigment losses (digestive efficiency) were greatest at low ingestion rates. They add that ingestion was positively correlated with food concentration. Thus, it seems reasonable to suggest that greater digestive efficiency occurs at low ingestion rates (low food concentration), whereas digestive efficiency may decrease at high ingestion rates (high food concentrations).

The laboratory experiments presented in this study underestimated microzooplankton grazing rates because the pigments were not completely degraded during grazing. However, chlorophyll a was degraded more readily at lower food concentrations. This result was achieved by comparing the grazing rates obtained from cell counts and chlorophyll a in each bottle of a dilution series. This allowed the average refractive portion of chlorophyll a at high and low food concentrations to be determined for each of the nine experiments. At an average initial food concentration of $5.1 * 10^{3}$ cells $\mathrm{ml}^{-1}$ the refractive portion of chlorophyll a averaged 0.45 . At an average initial food concentration of $2.2 * 10^{3}$ cells $\mathrm{ml}^{-1}$ the average refractive portion of chlorophyll a was reduced by $27 \%$ to 0.33 . This suggests that the amount of time pigments spend in the gut of a grazer, and thus the amount of pigment degradation, is related to the food concentration.

One discrepancy between this study and previous feeding experiments performed using oxyrrhis marina reported by 
Barlow et al. (1988) Klein et al. (1986), and Goldman et al. (1989) is apparent when examining the clearance rates calculated from each study. The three previous investigations were performed using very high food concentrations (approximately $1 * 10^{6} \mathrm{cells} \mathrm{ml}^{-1}$ ) which yielded clearance rates between $1.0 * 10^{-4}$ to $9.0 * 10^{-5} \mathrm{ml}$ grazer $^{-1} \mathrm{day}^{-1}$ for various food sources (Table 11). The laboratory experiments reported here were performed using food concentrations between approximately $1 * 10^{3}-9 * 10^{3}$ cells $\mathrm{ml}^{-1}$ which provided clearance rates between $2 * 10^{-3}-7 * 10^{-3} \mathrm{ml}$ grazer $^{-1} \mathrm{day}^{-1}$ for the same grazer fed the same food sources. For example, the clearance rates reported here using initial concentrations of phaeodactylum tricornutum of $5 * 10^{3}$ cell $\mathrm{ml}^{-1}$ are 100 times higher then reported using initial food concentrations of $2 * 10^{6}$ cells $\mathrm{ml}^{-1}$. Similarly, clearance rates reported here for Isochrysis galbana are 10 times higher then previously reported. This shows that Oxyrrhis marina is capable of being a much more efficient consumer at lower food concentrations and that very different feeding behaviors may have been displayed in previous experiments.

The laboratory experiments in this study also point out the need for accurate measurements of the initial phytoplankton concentration. One possible error associated with the dilution technique not previously considered in the literature is the potential error for phytoplankton growth rates to be underestimated due to the presence of undegraded 
pigment sequestered within the microzooplankton. Because of this, the initial pigment concentration is elevated which results in decreased phytoplankion growth rates. This was the result in many of the laboratory experiments presented here. For instance, before oxyrrhis was used in an experiment they were allowed to graze down their food source for approximately two to three days. If the food source was not completely grazed before the addition of oxyrrhis it would not result in an overestimation of the initial pigment concentration since initial biomass estimates were not made until after the dilutions were constructed. However, if the pigments contained inside the grazer remained intact the initial pigment concentration would be elevated resulting in low phytoplankton growth rates. Since some experiments provided growth rates which were much lower than others, it seems reasonable that the magnitude of the error is related to the amount of pigment contained within the grazers. Overall, the laboratory experiments presented here, using the grazer oxyrrhis, suggest that the microzooplankton grazing rates obtained from dilution experiments in the field should be considered conservative, if anything. Likewise, if microzooplankton contain intact phytoplankton pigments at the beginning of dilution experiments it is possible that the phytoplankton growth rates may also be underestimated, and should be given further consideration. Field experiments have shown that microzooplankton are capable of providing a significant portion of the grazing 
pressure. Combining this with the conclusion that the dilution technique provides minimal grazing rates provides evidence that microzooplankton may be even more important then previously realized. Furthermore, the finding that microzooplankton are important grazers in coastal environments, where microzooplankton and macrozooplankton co-exist, suggests that the food web for these regions may be more complicated then previously envisaged. 


\section{BIBLIOGRAPHY}

Andersson, A., C. Lee, F. Azam, and A. Hagstrom. 1985. Release of aminoacids and inorganic nutrients by heterotrophic marine microflagellates. Marine Ecology Progress Series. 23:99-106.

Barlow, R. G., P. H. Burkhill, and R. F. C. Mantoura. 1988. Grazing and degradation of algal pigments by marine protozoan oxyrrhis marina. Journal of Experimental Marine Biology and Ecology. 119:119-129.

Beers, J. R. and G. L. Stewart. 1971. Micro-zooplankters in the plankton communities of the upper waters of the eastern tropical Pacific. Deep Sea Research. 18:861883 .

Booth, B. C. 1987. The use of autofluorescence for analyzing oceanic phytoplankton communities. Botanica Marina. 30:101-108.

Burkhill, P. H., R. F. Mantoura, C. A. Llewellyn, and N. J. P. Owens. 1987. Microzooplankton grazing and selectivity of phytoplankton in coastal waters. Marine Biology - 93:581-590.

Campbell, I. and E. J. Carpenter. 1986. Estimating the grazing pressure on synechococcus spp. using the seawater dilution and selective inhibitor techniques. Marine Ecology Progress Series. 33:121-129.

Capriulo, G. M. and E. J. Carpenter. 1980. Grazing by 35 to 202 um micro-zooplankton in Long Island Sound. Marine Biology . 56:319-326.

Collos, Y. 1986. Time-lag algal growth dynamics: biological constraints on primary production in aquatic environments. Marine Ecology Progress Series. 33:193206 .

Conover, R. J., R. Durvasula, S. Roy, and R. Wang. 1986. Probable loss of chlorophyll-derived pigments during passage through the gut of zooplankton, and some of the consequences. Limnology and Oceanography. 31:878-887.

Dagg, M. J., and W. E. Walser, Jr. 1987. Ingestion, gut passage, and egestion by the copepod Neocalanus plumchrus in the laboratory and in the subarctic Pacific Ocean. Limnology and Oceanography. 32:178-188. 
Eppley, R. W. 1972. Temperature and phytoplankton growth in the sea. Fishery Bulletin. 70:1063-1085.

Frost, B. W. 1972. Effects of size and concentration of food particles on the feeding behavior of the marine planktonic copepod Calanus pacificus. Limnology and Oceanography $17: 805-815$.

Frost, B. W. 1980. Grazing. In: I. Morris (ed.), The Physiological Ecology of Phytoplankton. University of California Press. p. 465-491.

Gallegos, C. L. 1989. Microzooplankton grazing on phytoplankton in the Rhode River, Maryland: nonlinear feeding kinetics. Marine Ecology Progress Series. $57: 23-33$.

Gieskes, W. W. C., M. M. Engelkes, and G. W. Kraay. 1991. Degradation of diatom chlorophyll to colourless, nonfluorescing compounds during copepod grazing. Hydrobiological Bulletin. 25:65-72.

Gifford, D. J. 1985. Laboratory culture of marine planktonic oligotrichs (Ciliophora, Oligotrichida). Marine Ecology Progress Series. 23:257-267.

Gifford, D. J. 1988. Impact of grazing by microzooplankton in the Northwest Arm of Halifax Harbour, Nova Scotia. Marine Ecology Progress Series. 47:249-258.

Goldman, J. C. and D. A. Caron. 1985. Experimental studies on an omnivorous microflagellate: implications for grazing and nutrient regeneration in the marine microbial food chain. Deep Sea Research. 32:899-915.

Goldman, J. C., M. R. Dennett, and H. Gordin. 1989. Dynamics of herbivorous grazing by the heterotrophic dinoflagellate oxyrrhis marina. Journal of plankton Research. 11:391-407.

Heinbokel, J. F. 1978. Studies on the functional role of tintinnids in the Southern California Bight. 1. Grazing and growth rates in laboratory cultures. Marine Biology . 47:177-189.

Klein, B., W. C. Gieskes, and G. G. Kraay. 1986. Digestion of chlorophylls and carotenoids by the marine protozoan oxyrrhis marina studied by h.p.l.c. analysis of algal pigments. Journal of Plankton Research. 8:827-836. 
Landry, M. R. and R. P. Hassett. 1982. Estimating the grazing impact of marine micro-zooplankton. Marine Biology. $67: 283-288$.

Landry, M. R., L. W. Haas, and V. L. Fagerness. 1984 . Dynamics of microbial plankton communities: experiments in Kaneohe Bay, Hawaii. Marine Ecology Progress Series. $16: 127-133$.

Liaaen-Jensen, S. 1979. Carotenoids - A chemosystematic approach. Pure and Applied Chemistry. 51:661-675.

Lopez, M. D. G., M. E. Huntley, and P. F. Sykes. 1988. Pigment destruction by calanus pacificus: impact on the estimation of water column fluxes. Journal of plankton Research. 10:715-734.

Nelson, J. R. 1989. Phytoplankton pigments in macrozooplankton feces: variability in carotenoid alterations. Marine Ecology Progress Series. 52:129144.

Paasche, E. and S. Kristiansen. 1982. Ammonium regeneration by microzooplankton in the oslofjord. Marine Biology. $69: 55-63$.

Paranjape, M. A. 1987. Grazing by microzooplankton in the eastern Canadian arctic in summer 1983. Marine Ecology Progress Series. 40:239-246.

Pomeroy, I. R. 1974. The ocean's food web, a changing paradigm. Bioscience. 24:499-504.

Porter, K. G., and Y. S. Feig. 1980. The use of DAPI for identifying and counting aquatic microflora. Limnology and Oceanography. 25:943-948.

Real, L. A. 1977. The kinetics of functional response. The American Naturalist. 111:289-300.

Shuman, F. R., C. J. Lorenzen. 1975. Quantitative degradation of chlorophyll by a marine herbivore. Limnology and Oceanography. 20:580-586.

Silver, M. W., and P. J. Davoll. 1975. California cooperative investigations plankton data report. Monterey Bay. July 1974-July 1975. University of California, Santa Cruz. Coastal Marine Laboratory, Technical Report. Number 2. 88 pp. 
Silver, M. W., and P. J. Davoll. 1976. California cooperative investigations plankton data report. Monterey Bay. July 1975-July 1976. University of California, Santa Cruz. Coastal Marine Laboratory, Technical Report. Number 5. 169 pp.

Silver, M. W., and P. J. Davoll. 1977. California cooperative investigations plankton data report. Monterey Bay. July 1976-June 1977. University of California, Santa Cruz. Coastal Marine Laboratory, Technical Report. Number 8. 95 pp.

Stoecker, D. K., T. L. Cucci, E. M. Hulburt, and C. M. Yentsch. 1986. Journal of Experimental Marine Biology and Ecology. 95:113-130.

Stoecker, D. K. 1988. Are marine planktonic ciliates suspension feeders? Journal of Protozoology. 35:252255 .

Strom, S. L., and N. A. Welschmeyer. 1991. Pigment-specific rates of phytoplankton growth and microzooplankton grazing in the open subarctic Pacific Ocean. Limnology and Oceanography. 36:50-63.

Verity, P. G. 1988. Chemosensory behavior in marine planktonic ciliates. Bulletin of Marine Science. $43: 772-782$.

Wang, R. and R. J. Conover. 1986. Dynamics of gut pigment in the copepod Temora longicornis and the determination of in situ grazing rates. Limnology and Oceanography. 31:867-877.

Welschmeyer, N. A., and C. J. Lorenzen. 1985. Chlorophyll budgets: zooplankton grazing and phytoplankton growth in a temperate fjord and the Central Pacific Gyres. Limnology and Oceanography. 30:1-21. 
Table 1. Chlorophyll and major carotenoid pigments among classes of phytoplankton. $\mathrm{DD}=\mathrm{diadinoxanthin,}$ DT=diatoxanthin, $V=$ violaxanthin, $A=$ antheraxanthin, $\mathrm{z}=$ zeaxanthin.

\begin{tabular}{|c|c|c|}
\hline Class & Ch1 & Major Carotenoids \\
\hline $\begin{array}{l}\text { Cyanophyceae } \\
\text { (blue greens) }\end{array}$ & a & Zeaxanthin \\
\hline $\begin{array}{l}\text { Dinophyceae } \\
\text { (dinoflagellates) }\end{array}$ & $a, c$ & Peridinin, DD, DT \\
\hline $\begin{array}{l}\text { Chrysophyceae } \\
\text { (chrysophytes) }\end{array}$ & $a, c$ & $\begin{array}{l}\text { Fucoxanthin, DD, DT } \\
\text { 19'-butanoyloxyfucoxanthin }\end{array}$ \\
\hline $\begin{array}{l}\text { Haptophyceae } \\
\text { (haptophytes) }\end{array}$ & $a, c$ & $\begin{array}{l}\text { Fucoxanthin, DD, DT } \\
\text { 19'-butanoyioxyfucoxanthin }\end{array}$ \\
\hline Emiliania huxleyi & $\mathrm{c}_{3}$ & $19^{\prime}$-hexanoyloxy fucoxanthin \\
\hline $\begin{array}{l}\text { Bacillariophyceae } \\
\text { (diatoms) }\end{array}$ & $a^{2}, c$ & Fucoxanthin, DD, DT \\
\hline $\begin{array}{l}\text { Cryptophyceae } \\
\text { Prochlorophytes }\end{array}$ & $\begin{array}{ll}a, & c \\
a, & b\end{array}$ & $\begin{array}{l}\text { Alloxanthin } \\
\text { Zeaxanthin, Cryptoxanthin }\end{array}$ \\
\hline Chlorophytes & $a, b$ & Lutin, Neoxanthin, $V, A, Z$ \\
\hline Prasinophyceae & $a, b$ & $\begin{array}{l}\text { Prasinoxanthin, lutin, } \\
\text { Neoxanthin, } V, A, Z\end{array}$ \\
\hline
\end{tabular}

Table 2. Possible dilution experiment errors, and the results of such errors on the calculated microzooplankton grazing rates and phytoplankton growth rates.

\begin{tabular}{|c|c|c|}
\hline & Source of Error & Result \\
\hline 1) & Nutrient limited & $\begin{array}{l}\text { Overestimation of grazing rate, } \\
\text { possible slight overestimation } \\
\text { of phytoplankton growth }\end{array}$ \\
\hline 2) & $\begin{array}{l}\text { Addition of } \\
\text { nutrients }\end{array}$ & $\begin{array}{l}\text { Uncertain effects on } \\
\text { microzooplankton community, } \\
\text { may lead to elevated phyto- } \\
\text { plankton growth coefficients }\end{array}$ \\
\hline 3) & $\begin{array}{l}\text { Microzooplankton } \\
\text { food saturated }\end{array}$ & $\begin{array}{l}\text { Underestimation of grazing and } \\
\text { growth rates }\end{array}$ \\
\hline 4) & $\begin{array}{l}\text { Microzooplankton } \\
\text { feeding threshold }\end{array}$ & $\begin{array}{l}\text { overestimation of grazing and } \\
\text { growth rates }\end{array}$ \\
\hline 5) & $\begin{array}{l}\text { High initial food } \\
\text { concentration }\end{array}$ & $\begin{array}{l}\text { Underestimation of growth rate } \\
\text { no effect on grazing rate }\end{array}$ \\
\hline 6) & $\begin{array}{l}\text { Low initial food } \\
\text { concentration }\end{array}$ & $\begin{array}{l}\text { Overestimation of growth rate } \\
\text { no effect on grazing rate }\end{array}$ \\
\hline
\end{tabular}


Table 3. Solvent gradient used to separate pigments. Solvent $A=85 \%$ methanol $15 \%$ ammonium acetate, $B=$ methanol, and $\mathrm{C}=$ acetone.

\begin{tabular}{|crrr|}
\hline Time (min) & $\% \mathrm{~A}$ & $\% \mathrm{~B}$ & $\% \mathrm{C}$ \\
\hline 0 & 100 & 0 & 0 \\
8 & 0 & 85 & 15 \\
13 & 0 & 70 & 30 \\
17 & 0 & 20 & 80 \\
26 & 0 & 20 & 80 \\
29 & 100 & 0 & 0 \\
31 & 100 & 0 & 0 \\
\hline
\end{tabular}

Table 4. The peak areas of major pigments from four food sources extracted by soaking and grinding. $19^{\prime}$-hex $=19^{\prime}-$ hexanoyloxyfucoxanthin.

\begin{tabular}{|c|c|c|c|}
\hline Food Source & Pigment & Soaking & Grinding \\
\hline \multirow[t]{6}{*}{ Gymnodinjum } & $\operatorname{chl}$ a & 1809 & 2026 \\
\hline & & 1808 & 1828 \\
\hline & & 1928 & 1733 \\
\hline & peridinin & 956 & 1052 \\
\hline & & 944 & 939 \\
\hline & & 1024 & 913 \\
\hline \multirow[t]{9}{*}{ Isochrysis } & ch1 a & 249 & 255 \\
\hline & & 264 & 284 \\
\hline & & 242 & 274 \\
\hline & fucoxanthin & 178 & 186 \\
\hline & & 177 & 176 \\
\hline & & 183 & 188 \\
\hline & $\operatorname{chl} \underline{c}$ & 88 & 96 \\
\hline & & 94 & 93 \\
\hline & & 96 & 87 \\
\hline \multirow[t]{9}{*}{ PhaeodactyIum } & chl a & 120 & 99 \\
\hline & & 113 & 115 \\
\hline & & 104 & 116 \\
\hline & fucoxanthin & 257 & 279 \\
\hline & & 263 & 255 \\
\hline & & 255 & 296 \\
\hline & $\operatorname{chl} \underline{c}$ & 82 & 91 \\
\hline & & 91 & 84 \\
\hline & & 87 & 89 \\
\hline \multirow[t]{6}{*}{ Emiliania } & $\operatorname{ch} 1$ a & 99 & 103 \\
\hline & & 95 & 102 \\
\hline & & 100 & 118 \\
\hline & $19^{\prime}$-hex & 144 & 151 \\
\hline & & 148 & 148 \\
\hline & & 148 & 163 \\
\hline
\end{tabular}


Table 5. The true grazing $(g)$ and growth $(u)$ rates $\left(d^{-1}\right)$ obtained from cell counts and, grazing and growth rates (with $95 \%$ confidence intervals) from dilution plots provided by each pigment in the three laboratory experiments with Symnodinium sp. which contained peridinin. The grazing rate is obtained from the negative slope of the dilution plot. However, some plots showed a slightly positive slope. The results provided by these plots are in parentheses. ChI

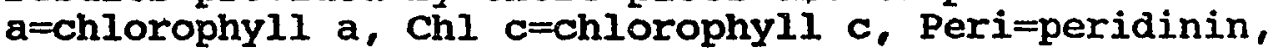
DD=diadinoxanthin, B-car=beta-carotene.

\begin{tabular}{|c|c|c|c|c|c|c|}
\hline Exp & Rates & chl a & Chl c & Peri & DD & B-car \\
\hline $1 \underset{\mathrm{u}}{\mathrm{g}}$ & $\begin{array}{l}g=0.25 \pm 0.12 \\
u=0.00 \pm 0.06\end{array}$ & $\begin{array}{r}0.12 \pm 0.25 \\
-0.27 \pm 0.09\end{array}$ & $\begin{array}{r}0.00 \pm 0.18 \\
-0.04 \pm 0.09\end{array}$ & $\begin{array}{l}0.06 \pm 0.11 \\
0.00 \pm 0.04\end{array}$ & $\begin{array}{l}0.07 \pm 0.08 \\
0.02 \pm 0.04\end{array}$ & $\begin{array}{l}0.15 \pm 0.22 \\
0.05 \pm 0.09\end{array}$ \\
\hline $2 \underset{v}{\mathrm{u}}$ & $\begin{array}{l}g=0.09 \pm 0.16 \\
u=0.00 \pm 0.03\end{array}$ & $\begin{array}{r}0.00 \pm 0.11 \\
-0.16 \pm 0.05\end{array}$ & $\begin{array}{r}0.00 \pm 0.11 \\
-0.11 \pm 0.05\end{array}$ & $\begin{array}{r}0.02 \pm 0.08 \\
-0.05 \pm 0.03\end{array}$ & $\begin{array}{r}0.04 \pm 0.05 \\
-0.04 \pm 0.02\end{array}$ & $\begin{array}{l}(0.03) \pm 0.15 \\
-0.16 \pm 0.06\end{array}$ \\
\hline $3 \underset{u}{g}$ & $\begin{array}{l}g=0.21 \pm 0.07 \\
u=0.00 \pm 0.05\end{array}$ & $\begin{array}{l}(0.01) \pm 0.15 \\
-0.05 \pm 0.12\end{array}$ & $\begin{array}{l}(0.04) \pm 0.14 \\
-0.03 \pm 0.12\end{array}$ & $\begin{array}{l}0.02 \pm 0.11 \\
0.01 \pm 0.09\end{array}$ & $\begin{array}{r}0.01 \pm 0.12 \\
-0.06 \pm 0.09\end{array}$ & $\begin{array}{l}(0.06) \pm 0.10 \\
-0.08 \pm 0.08\end{array}$ \\
\hline
\end{tabular}

Table 6. The ratio of observed grazing rates:true grazing rates provided by each pigment in the nine laboratory experiments. Samples with slight positive slopes in parentheses were considered to have slopes of zero. 19 'hexanoyloxyfucoxanthin $(*)$, Chlorophyll $c_{3}(+)$. Chl $a=$ chlorophyll a, Chl $c=$ chlorophyll $c ;$ Fuco=fucoxanthin, Peri=peridinin, $\mathrm{DD}=$ diadinoxanthin, $\mathrm{B}$-car=beta-carotene.

\begin{tabular}{|lccllll|}
\hline Exp. & Chl a & Chl c & Fuco & Peri & DD & B-car \\
\hline 1 & 0.48 & 0.00 & - & 0.24 & 0.28 & 0.60 \\
2 & 0.00 & 0.00 & - & 0.22 & 0.44 & $(0.00)$ \\
3 & $(0.00)$ & $(0.00)$ & - & 0.10 & 0.05 & $(0.00)$ \\
4 & 0.58 & 0.45 & 0.35 & - & - & 0.35 \\
5 & 0.59 & 0.76 & 0.24 & - & 0.24 & 0.29 \\
6 & 0.34 & 0.30 & 0.22 & - & 0.22 & 0.04 \\
7 & 0.48 & 0.35 & 0.31 & - & - & 0.38 \\
8 & 0.90 & $1.08+$ & $0.52 *$ & - & - & - \\
9 & 1.30 & $1.33+$ & $0.77 *$ & - & 0.67 & 0.97 \\
\hline
\end{tabular}


Table 7. The true grazing $(g)$ and $\operatorname{growth}(u)$ rates $\left(d^{-1}\right)$ obtained from cell counts and, grazing and growth rates (95\% confidence intervals) from dilution plots provided by each pigment in the six laboratory experiments using Emiliania huxleyi which contains $19^{\prime}$ hexanoyloxyfucoxanthin and Phaeodactylum tricornutum and Isechrysis galbana which both contain fucoxanthin. 19'hexanoyloxyfucoxanthin (*), Chlorophyll $c_{3}(+)$. Chl a=chlorophyll a, Chl c=chlorophyll c, Fuco=fucoxanthin, DD=diadinoxanthin, $\mathrm{B}$-car=beta-carotene. Not determined $=$ nd.

\begin{tabular}{|c|c|c|c|c|c|c|}
\hline Exp & Rates & Chl a & ChI c & Fuco & DD & B-car \\
\hline 4 & $\begin{array}{l}g=0.60 \pm 0.14 \\
u=0.00 \pm 0.11\end{array}$ & $\begin{array}{r}0.35 \pm 0.21 \\
-0.35 \pm 0.16\end{array}$ & $\begin{array}{r}0.27 \pm 0.14 \\
-0.34 \pm 0.11\end{array}$ & $\begin{array}{r}0.21 \pm 0.18 \\
-0.26 \pm 0.14\end{array}$ & $\begin{array}{l}\text { nd } \\
\text { nd }\end{array}$ & $\begin{array}{r}0.21 \pm 0.21 \\
-0.23 \pm 0.17\end{array}$ \\
\hline 5 & $\begin{array}{l}g=0.17 \pm 0.12 \\
u=0.00 \pm 0.10\end{array}$ & $\begin{array}{r}0.10 \pm 0.05 \\
-0.08 \pm 0.04\end{array}$ & $\begin{array}{l}0.13 \pm 0.18 \\
0.00 \pm 0.13\end{array}$ & $\begin{array}{l}0.04 \pm 0.05 \\
0.02 \pm 0.04\end{array}$ & $\begin{array}{l}0.04 \pm 0.05 \\
0.05 \pm 0.04\end{array}$ & $\begin{array}{r}0.05 \pm 0.05 \\
-0.02 \pm 0.03\end{array}$ \\
\hline 6 & $\begin{array}{l}g=0.23 \pm 0.15 \\
u=0.00 \pm 0.12\end{array}$ & $\begin{array}{r}0.08 \pm 0.13 \\
-0.21 \pm 0.11\end{array}$ & $\begin{array}{r}0.07 \pm 0.12 \\
-0.21 \pm 0.09\end{array}$ & $\begin{array}{r}0.05 \pm 0.04 \\
-0.08 \pm 0.04\end{array}$ & $\begin{array}{r}0.05 \pm 0.08 \\
-0.06 \pm 0.06\end{array}$ & $\begin{array}{r}0.01 \pm 0.06 \\
-0.03 \pm 0.05\end{array}$ \\
\hline 7 & $\begin{array}{l}g=0.71 \pm 0.15 \\
u=0.00 \pm 0.11\end{array}$ & $\begin{array}{r}0.34 \pm 0.14 \\
-0.15 \pm 0.09\end{array}$ & $\begin{array}{r}0.25 \pm 0.11 \\
-0.21 \pm 0.07\end{array}$ & $\begin{array}{r}0.22 \pm 0.07 \\
-0.17 \pm 0.05\end{array}$ & $\begin{array}{l}\text { nd } \\
\text { nd }\end{array}$ & $\begin{array}{r}0.27 \pm 0.14 \\
-0.11 \pm 0.09\end{array}$ \\
\hline 8 & $\begin{array}{l}g=1.03 \pm 0.19 \\
u=0.00 \pm 0.16\end{array}$ & $\begin{array}{l}0.93 \pm 0.26 \\
0.04 \pm 0.19\end{array}$ & $\begin{array}{l}1.11 \pm 0.32+ \\
-0.05 \pm 0.25\end{array}$ & $\begin{array}{l}0.54 \pm 0.14 * \\
0.08 \pm 0.11\end{array}$ & $\begin{array}{l}\text { nd } \\
\text { nd }\end{array}$ & $\begin{array}{l}\text { nd } \\
\text { nd }\end{array}$ \\
\hline 9 & $\begin{array}{l}g=0.30 \pm 0.09 \\
u=0.00 \pm 0.07\end{array}$ & $\begin{array}{r}0.39 \pm 0.14 \\
-0.22 \pm 0.11\end{array}$ & $\begin{array}{r}0.40 \pm 0.11+ \\
-0.22 \pm 0.08\end{array}$ & $\begin{array}{l}0.23 \pm 0.09 * \\
-0.15 \pm 0.07\end{array}$ & $\begin{array}{r}0.20 \pm 0.10 \\
-0.26 \pm 0.07\end{array}$ & $\begin{array}{r}0.29 \pm 0.23 \\
-0.12 \pm 0.18\end{array}$ \\
\hline
\end{tabular}


Table 8. Phytoplankton growth and microzooplankton grazing rates (with $95 \%$ confidence intervals) determined for specific pigments for experiments performed at depths of 0 , 10, and $20 \mathrm{~m}$ in September 1991 in Monterey Bay, California. Coefficients of determination $\left(r^{2}\right)$ for all regressions are given. Not Determined=nd. $19^{\prime}-$ But $=19^{\prime}-$ Butanoyloxyfucoxanthin.

\begin{tabular}{|lccc|}
\hline Pigment & Growth & Grazing & $\mathrm{r}^{2}$ \\
\hline 0 Meters & & & \\
Chl a & $0.53 \pm 0.34$ & $0.37 \pm 0.47$ & 0.38 \\
Chl c & $0.53 \pm 0.34$ & $0.19 \pm 0.47$ & 0.14 \\
Fucoxanthin & $0.62 \pm 0.24$ & $0.59 \pm 0.33$ & 0.77 \\
19'-But & $0.19 \pm 0.50$ & $0.30 \pm 0.68$ & 0.16 \\
Beta-Carotene & $0.83 \pm 0.30$ & $0.50 \pm 0.41$ & 0.60 \\
Zeaxanthin & $1.97 \pm 0.39$ & $1.51 \pm 0.53$ & 0.89 \\
10 Meters & & & \\
Chl a & & & \\
Chl c & $1.07 \pm 0.13$ & $0.79 \pm 0.18$ & 0.95 \\
Fucoxanthin & $0.37 \pm 0.21$ & $0.21 \pm 0.29$ & 0.34 \\
19'-But & $0.40 \pm 0.23$ & $0.27 \pm 0.31$ & 0.43 \\
Beta-Carotene & $0.71 \pm 0.26$ & $0.62 \pm 0.36$ & 0.75 \\
Zeaxanthin & $2.81 \pm 0.18$ & $2.09 \pm 0.25$ & 0.99 \\
& & & \\
20 Meters & & $0.37 \pm 0.20$ & 0.80 \\
Chl a & $0.61 \pm 0.13$ & 0.37 & 0.75 \\
Chl c & $0.61 \pm 0.12$ & $0.31 \pm 0.20$ & 0.72 \\
Fucoxanthin & $0.59 \pm 0.19$ & $0.46 \pm 0.31$ & 0.48 \\
19'-But & $0.52 \pm 0.24$ & $0.32 \pm 0.33$ & 0.92 \\
Beta-Carotene & $0.64 \pm 0.09$ & $0.49 \pm 0.15$ & 0.67 \\
Peridinin & $0.76 \pm 0.37$ & $0.77 \pm 0.59$ & \\
\hline
\end{tabular}


Table 9. Phytoplankton growth and microzooplankton grazing rates (with 95\% confidence intervals) determined for

specific pigments for experiments performed at depths of 20 and $35 \mathrm{~m}$ in March 1992 in Monterey Bay, California.

Coefficients of determination $\left(r^{2}\right)$ for all regressions are

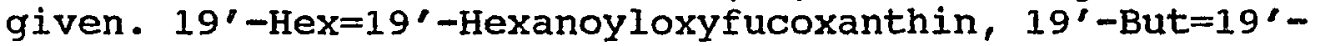
Butanoyloxyfucoxanthin.

\begin{tabular}{|lccc|}
\hline Pigment & Growth & Grazing & $\mathrm{r}^{2}$ \\
\hline 20 Meters & & & \\
Chl a & $1.30 \pm 0.10$ & $0.38 \pm 0.15$ & 0.89 \\
Chl b & $1.38 \pm 0.12$ & $0.14 \pm 0.25$ & 0.35 \\
Chl c & $1.10 \pm 0.19$ & $0.26 \pm 0.28$ & 0.52 \\
Fucoxanthin & $1.06 \pm 0.15$ & $0.34 \pm 0.22$ & 0.74 \\
19'-Hex & $0.75 \pm 0.20$ & $0.27 \pm 0.28$ & 0.52 \\
19'-But & $0.74 \pm 0.38$ & $0.57 \pm 0.54$ & 0.58 \\
Beta-Carotene & $1.55 \pm 0.36$ & $0.03 \pm 0.51$ & 0.00 \\
Zeaxanthin & $2.40 \pm 0.44$ & $0.17 \pm 0.63$ & 0.08 \\
& & & \\
35 Meters & & & \\
Chl a & $0.80 \pm 0.03$ & $0.23 \pm 0.05$ & 0.96 \\
Chl b & $0.85 \pm 0.15$ & $0.12 \pm 0.21$ & 0.27 \\
Chl c & $0.97 \pm 0.08$ & $0.24 \pm 0.12$ & 0.83 \\
Fucoxanthin & $1.14 \pm 0.07$ & $0.31 \pm 0.11$ & 0.91 \\
19'-Hex & $0.87 \pm 0.11$ & $0.42 \pm 0.16$ & 0.89 \\
19'-But & $1.02 \pm 0.11$ & $0.47 \pm 0.16$ & 0.92 \\
Beta-Carotene & $0.83 \pm 0.13$ & $0.08 \pm 0.19$ & 0.16 \\
Zeaxanthin & $1.10 \pm 0.16$ & $0.13 \pm 0.23$ & 0.28 \\
Alloxanthin & $1.17 \pm 0.28$ & $0.58 \pm 0.40$ & 0.72 \\
\hline
\end{tabular}


Table 10. Summary of previous microzooplankton community grazing pressures reported for various regions. Grazing pressure is the percent of the standing stock grazed daily.

\begin{tabular}{|c|c|c|}
\hline Location & \multicolumn{2}{|c|}{ Grazing Pressure References } \\
\hline North-Eastern Pacific & $6-24 \%$ & Landry and Hassett 1982 \\
\hline $\begin{array}{l}\text { Kaneohe Bay } \\
\text { Hawaii }\end{array}$ & $29-37 \%$ & Landry et al. 1984 \\
\hline Celtic Sea & $30-65 \%$ & Burkhill et al. 1987 \\
\hline Canadian Arctic & $8-15 \%$ & Paranjape 1987 \\
\hline $\begin{array}{l}\text { Halifax Harbor } \\
\text { Nova Scotia }\end{array}$ & $21-50 \%$ & Gifford 1988 \\
\hline Subarctic Pacific & $5-27 \%$ & Strom and Welschmeyer 1991 \\
\hline $\begin{array}{l}\text { Monterey Bay } \\
\text { California }\end{array}$ & $21-55 \%$ & This study \\
\hline
\end{tabular}

Table 11. Clearance rates ( $\mathrm{ml}$ grazer $^{-1} \mathrm{day}^{-1}$ ) obtained for oxyrrhis marina, under initial food concentrations of $1 * 10^{6}$ and $1 * 10^{3}$ cells $\mathrm{ml}^{-1}$, using the food sources phaeodactylum tricornutum, Isochrysis galbana, Rhodomonas sp., Gymnodinium sp., and Emiliania huxleyi.

\begin{tabular}{|lllll|}
\hline \multicolumn{2}{|l}{ Clearance Food Source } & Initial Conc. & References \\
\hline $1 * 10^{-4}$ & Rhodomonas sp. & $3 * 10^{5}$ & Klein et al. & 1986 \\
$9 * 10^{-5}$ & P. tricornutum & $2 * 10^{6}$ & Barlow et al. & 1988 \\
$3 * 10^{-4}$ & I. galbana & $2 * 10^{6}$ & & \\
$5 * 10^{-5}$ & P. tricornutum & $7 * 10^{6}$ & Goldman et al. & 1989 \\
$4 * 10^{-4}$ & I. galbana & $2 * 10^{6}$ & & \\
$7 * 10^{-3}$ & P. tricornutum & $5 * 10^{3}$ & This study & \\
$3 * 10^{-3}$ & I. galbana & $6 * 10^{3}$ & & \\
$2 * 10^{-3}$ & Gymnodinium sp. & $6 * 10^{3}$ & & \\
$2 * 10^{-3}$ & E. huxleyi & $5 * 10^{3}$ & & \\
\hline
\end{tabular}



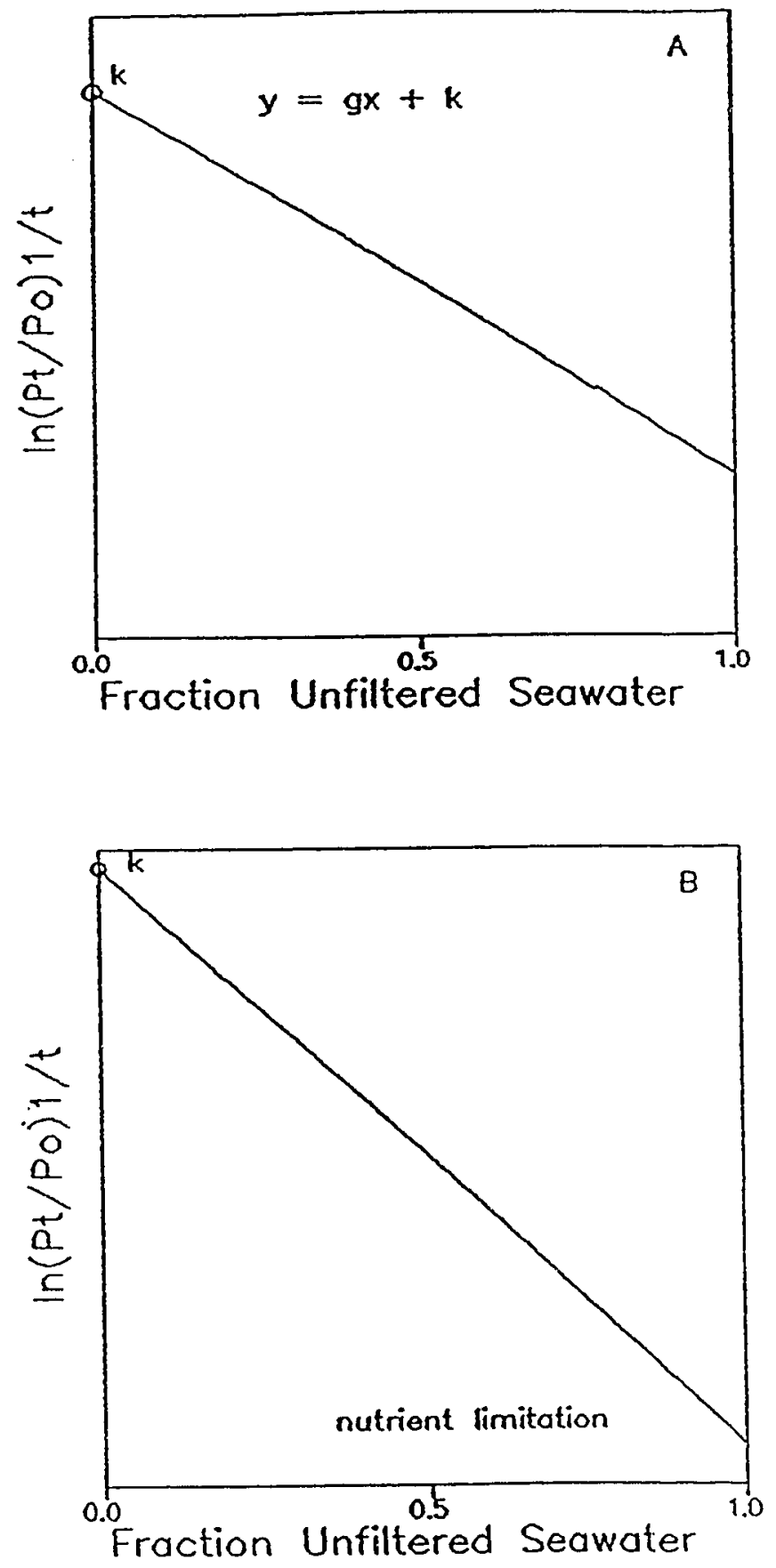

Figure 1. The ideal dilution model (A) and the dilution model under nutrient limitation showing an exaggerated slope and increased phytoplankton growth rate ( $k$, redrawn from Gifford 1988). 


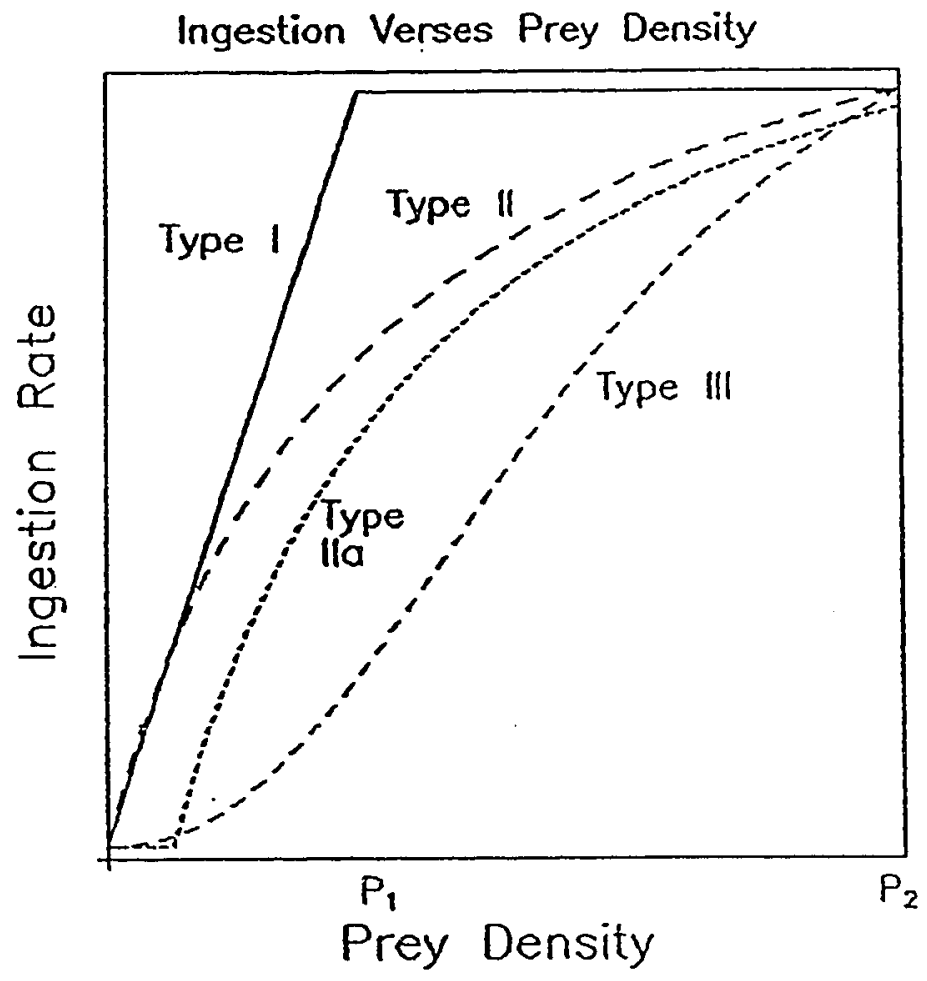

Figure 2. Generalized functional response curves recognized in predator-prey dynamics. Points $\mathrm{P} 1$ and $\mathrm{p} 2$ were used as initial prey densities for generating curves in Figure 3 . 

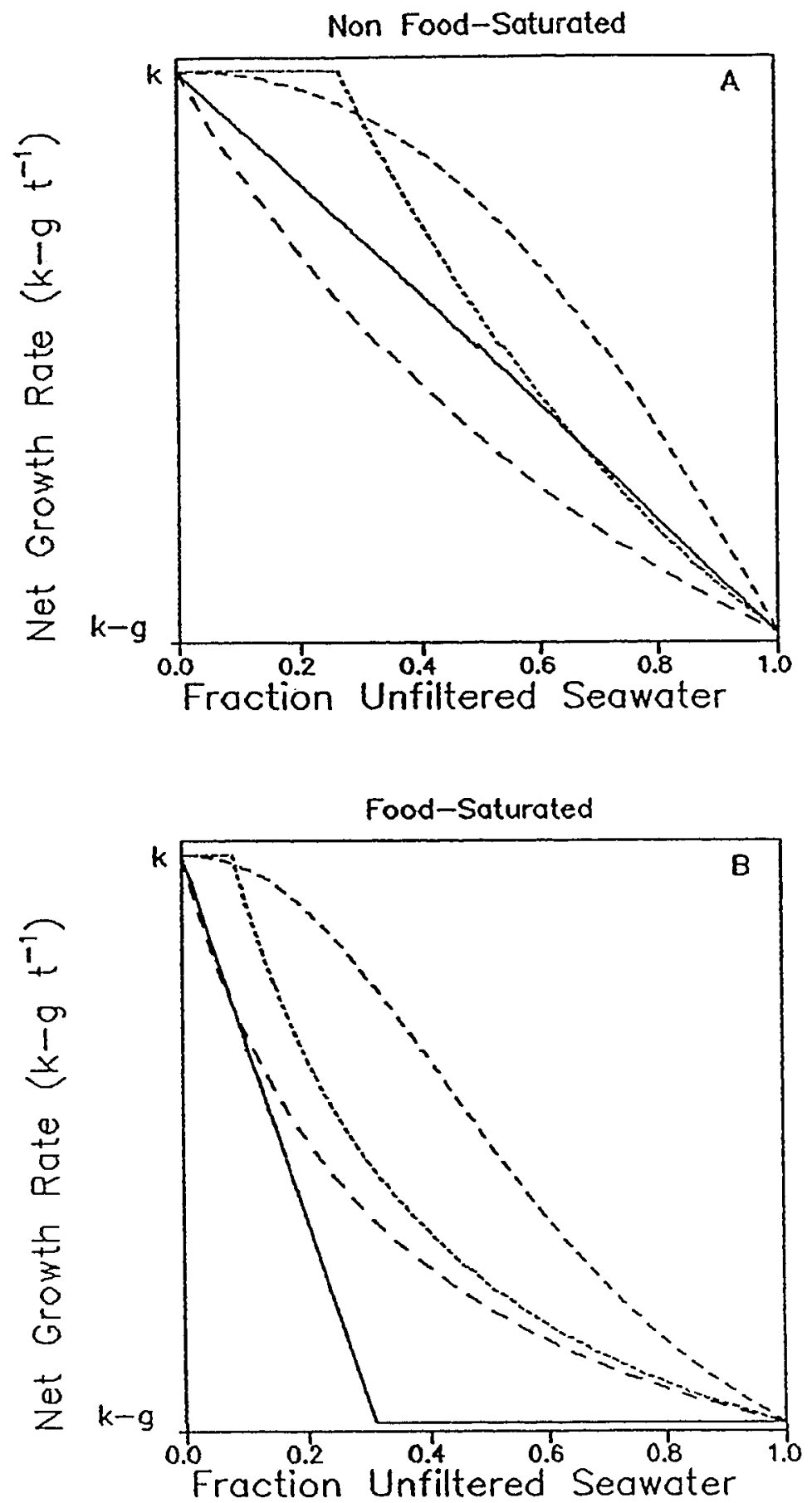

Figure 3. Curves of net growth rate versus fraction unfiltered seawater generated using functional response curves shown in Figure 2. (A) initial prey density $=\mathrm{P1}$; (B) initial prey density $=\mathrm{P} 2$. 


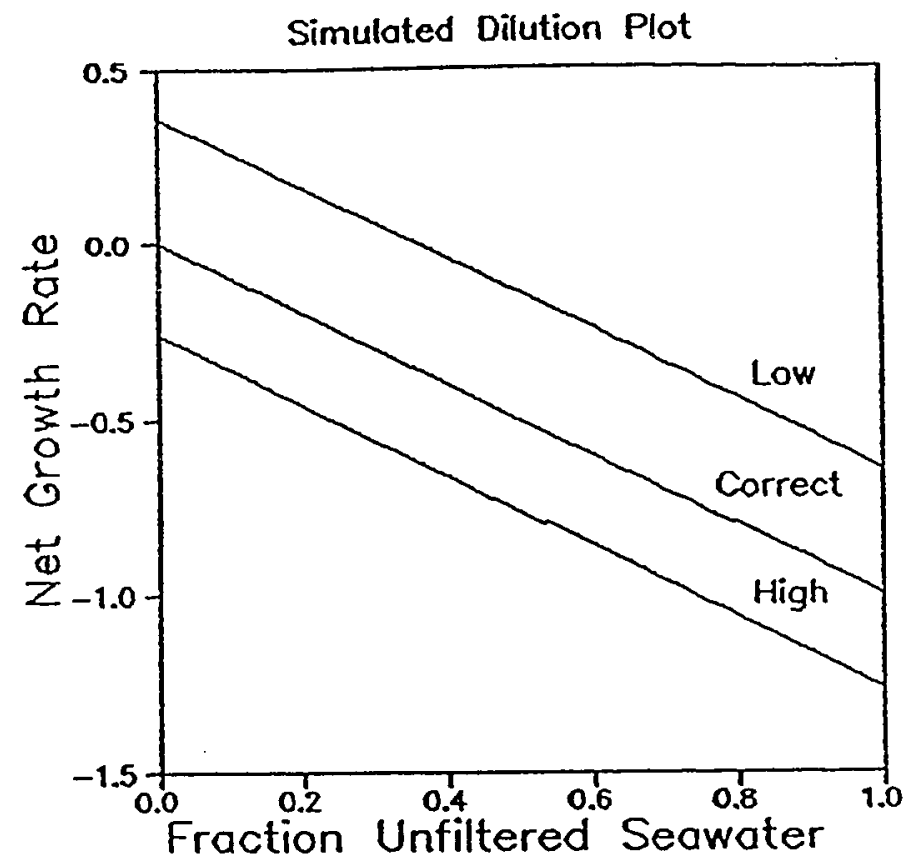

Figure 4. Net growth rate versus fraction unfiltered seawater using three different initial phytoplankton concentrations. A low initial value leads to an overestimation of net growth whereas a high initial value leads to an underestimation of net growth.

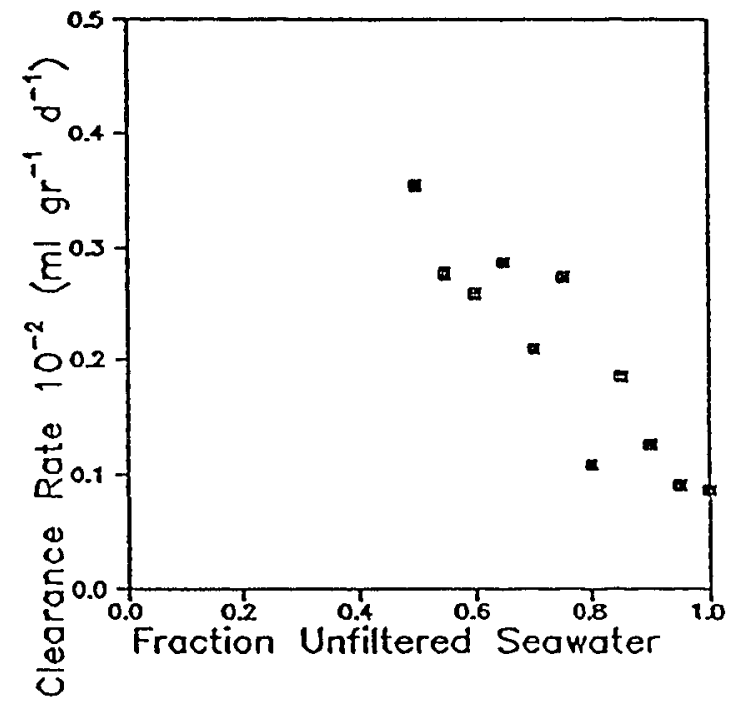

Figure 5. Clearance rates ( $\mathrm{ml}$ grazer $^{-1} \mathrm{day}^{-1}$ ) versus fraction unfiltered seawater showing increasing clearance rates with dilution. The initial food concentration for this dilution experiment was approximately $2 * 10^{4}$ cells $\mathrm{mI}^{-1}$. 


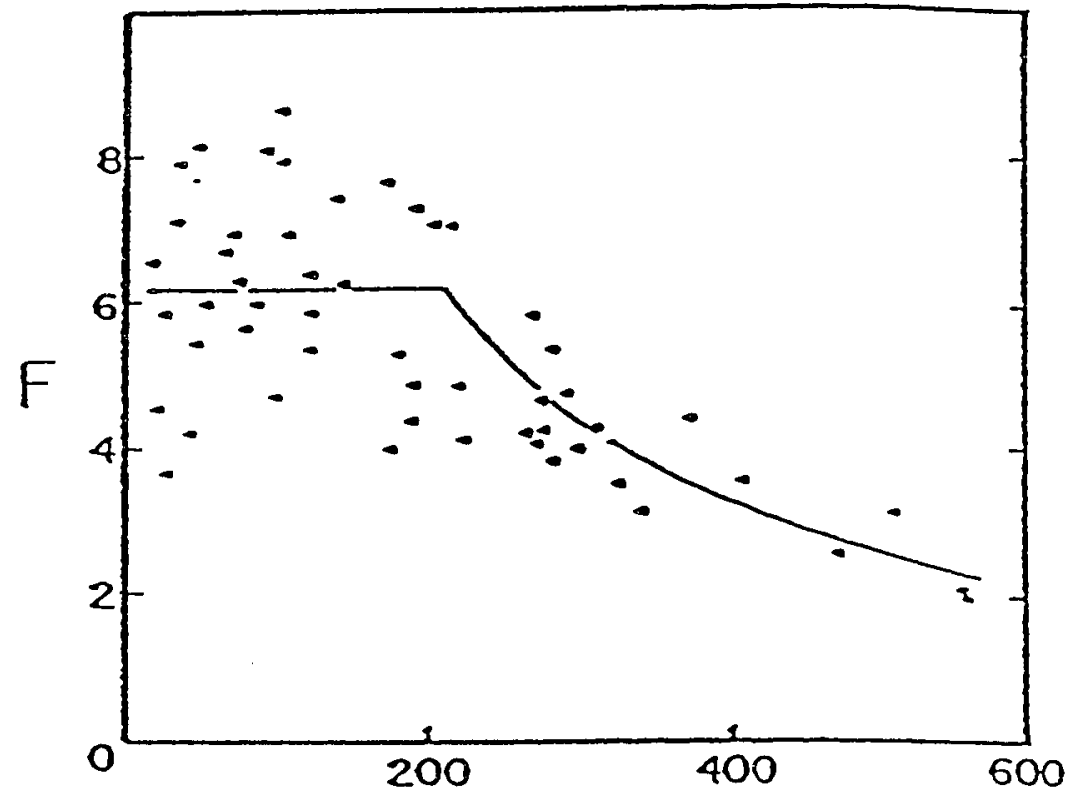

CELLS/ML

Figure 6. Clearance rates ( $F, \mathrm{ml}$ grazer $^{-1}$ day $^{-1}$ ) versus food concentration (cells $\mathrm{ml}^{-1}$ ) showing a decrease in apparent clearance rate with increasing food concentration (Frost 1972). 

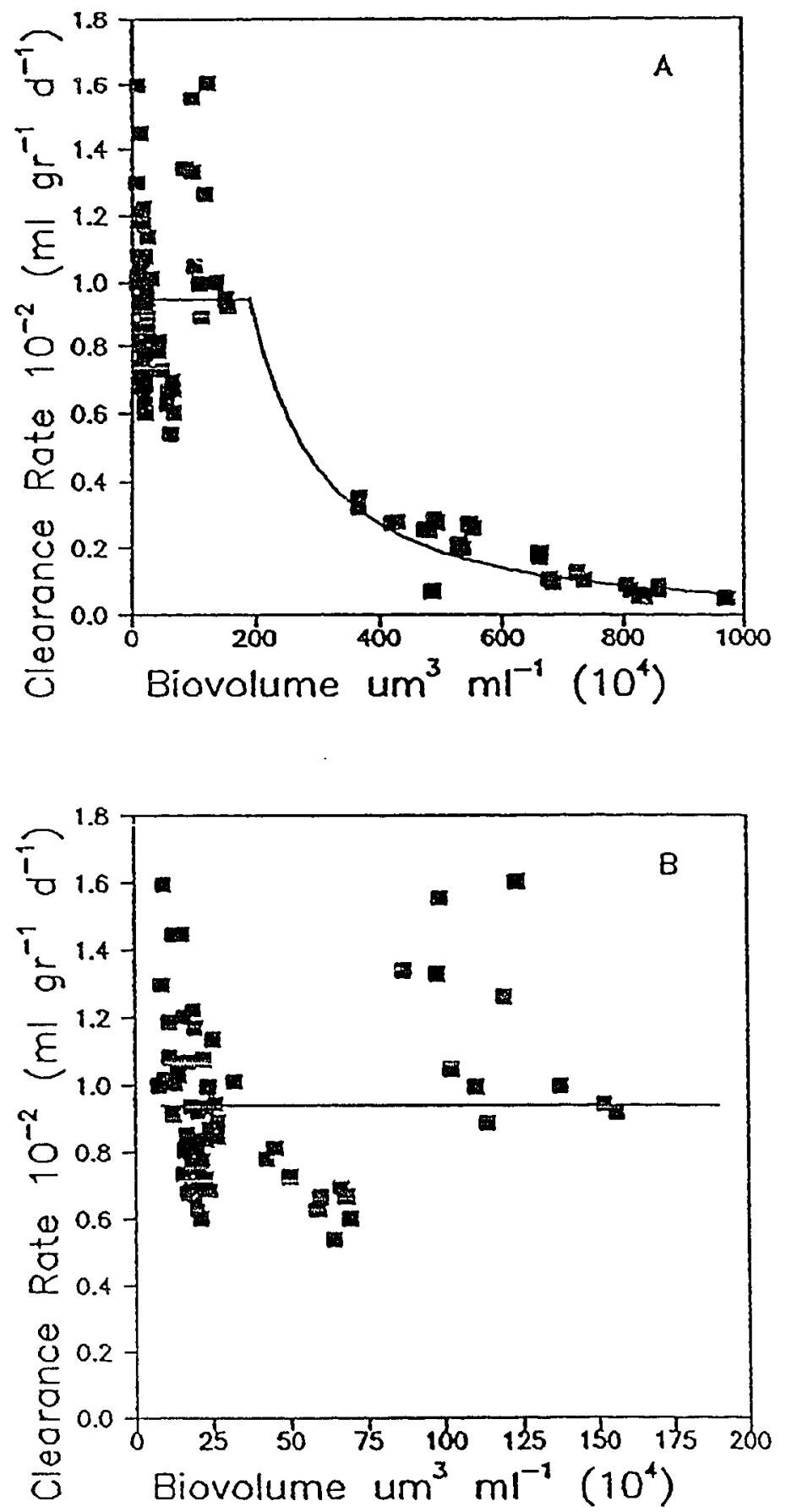

Figure 7. Clearance rates (ml grazer $^{-1}$ day ${ }^{-1}$ ) versus food biovolume. (A) shows decreasing clearance rates with increasing biovolume and (B) shows fairly constant clearance rates between biovolumes of approximately $10 * 10^{4}$ to $175 * 10^{4}$. 

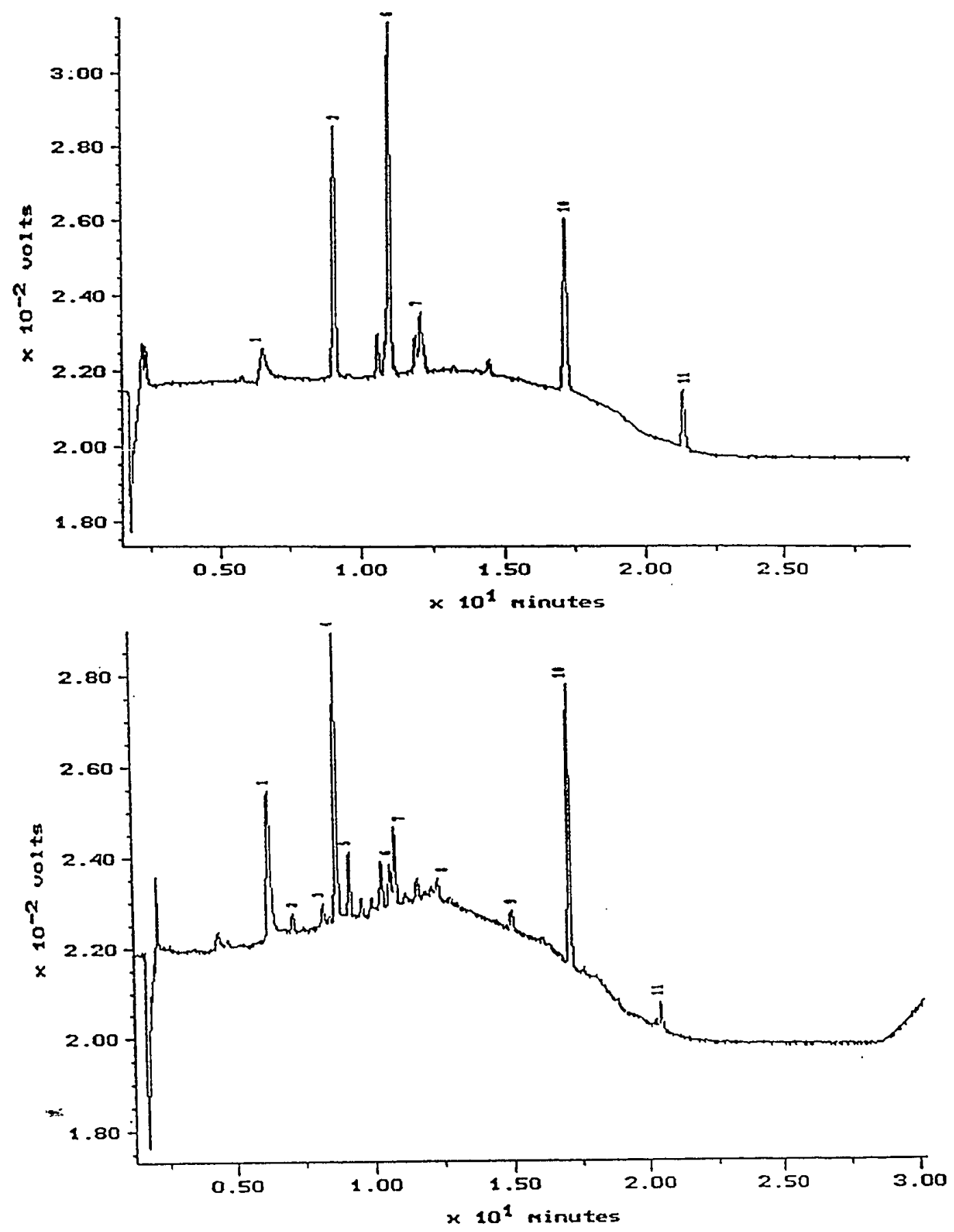

Figure 8. (A) Chromatogram from a laboratory experiment with Gymnodinium sp. (B) chromatogram from a field experiment at the surface in Monterey Bay. $1=\mathrm{chl}$ c, 2=peridinin, 3=19'butanoyloxyfucoxanthin, $4=$ fucoxanthin, 5=19'-

hexanoyloxyfucoxanthin, 6=diadinoxanthin, 7=diatoxanthin, $8=$ zeaxanthin, $9=\mathrm{chl} b, 10=\mathrm{chl} a, 11=$ beta-carotene. 

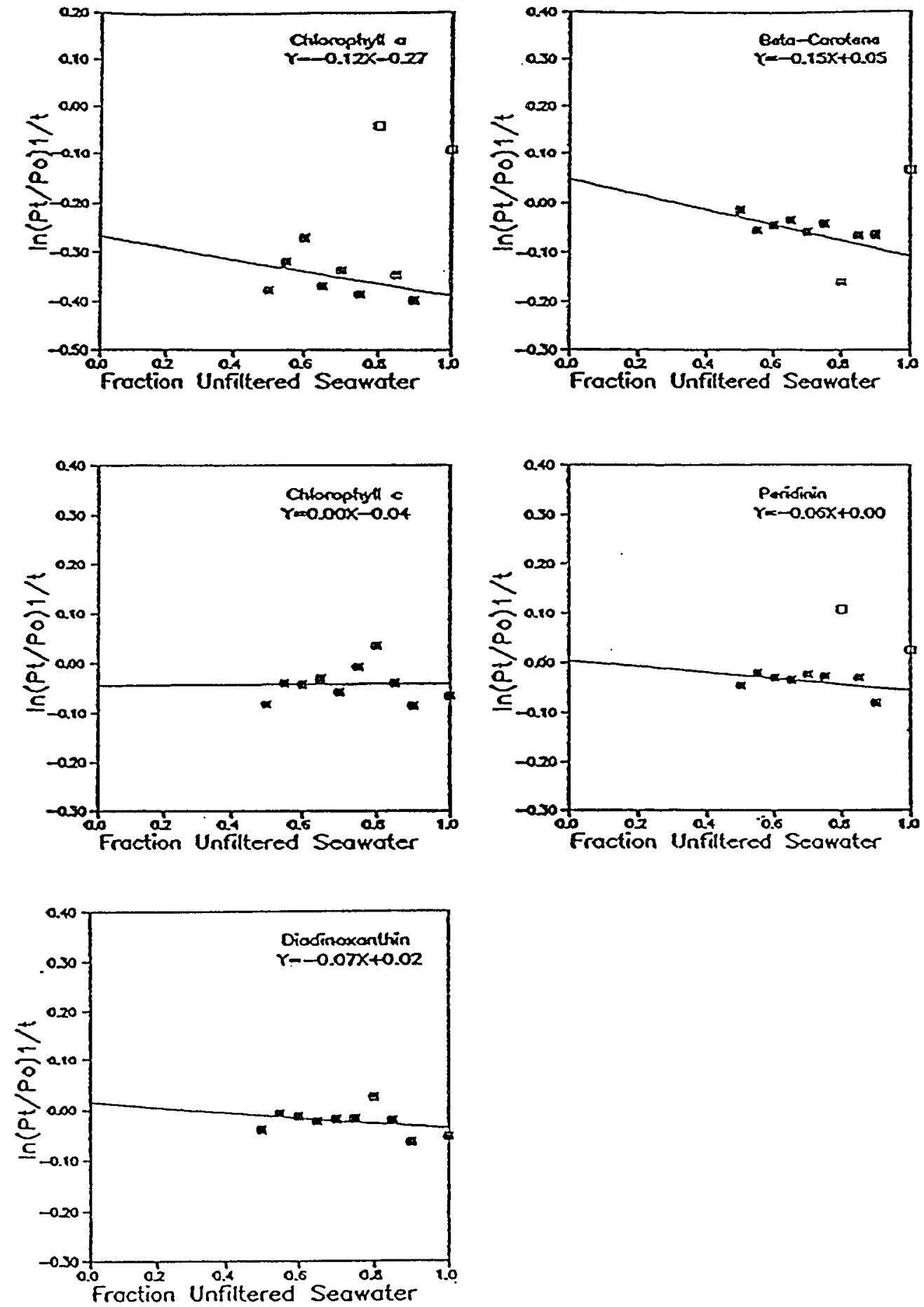

Figure 9. Dilution plots (net growth rate versus dilution factor) for pigments analyzed in experiment \#1 with Gymnodinium $\mathrm{sp}$. as the food source. Empty squares represent data points which were not included in the linear regression. Linear regression data are shown. 


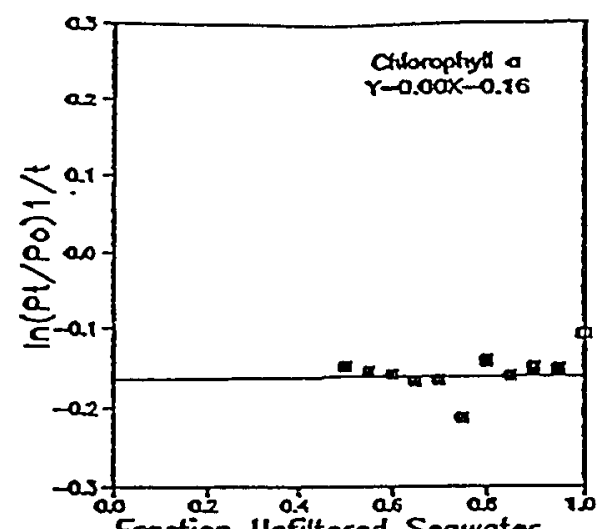

Fraction Unfiltered Seawoter
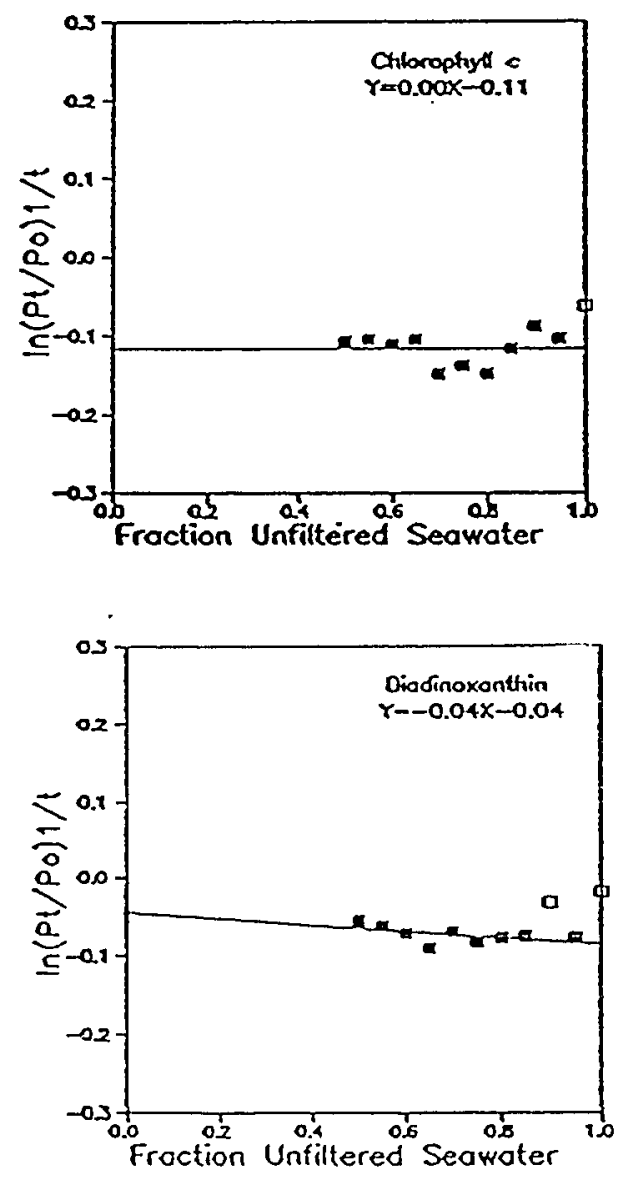
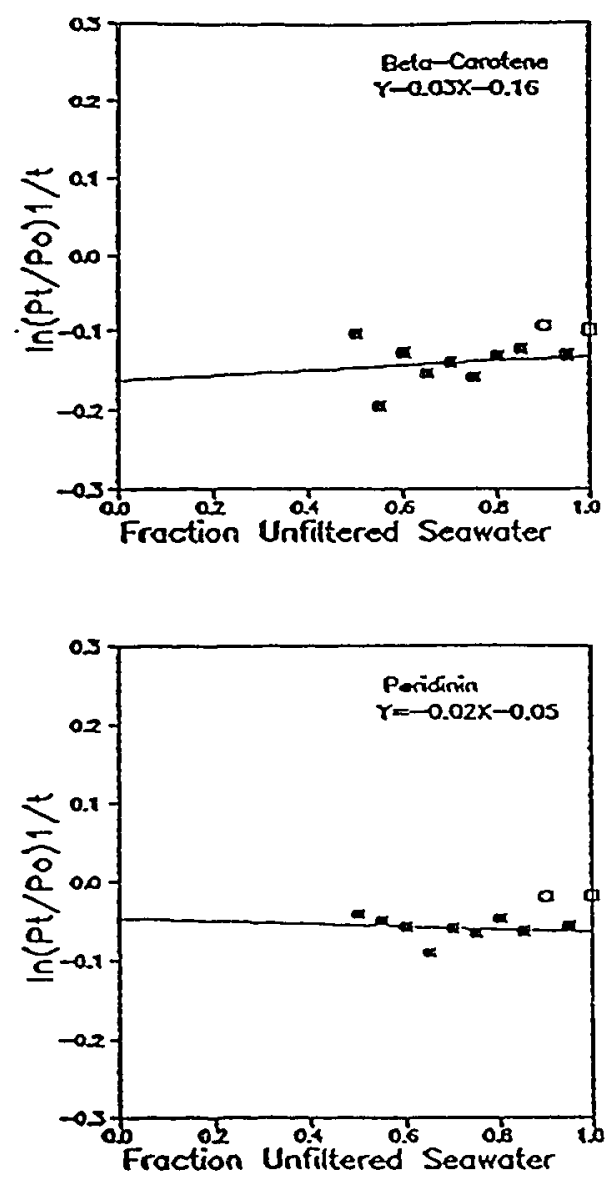

Figure 10. Dilution plots (net growth rate versus dilution factor) for pigments analyzed in experiment \#2 with Gymnodinium $\mathrm{sp}$. as the food source. Empty squares represent data points which were not included in the linear regression. Linear regression data are shown. 

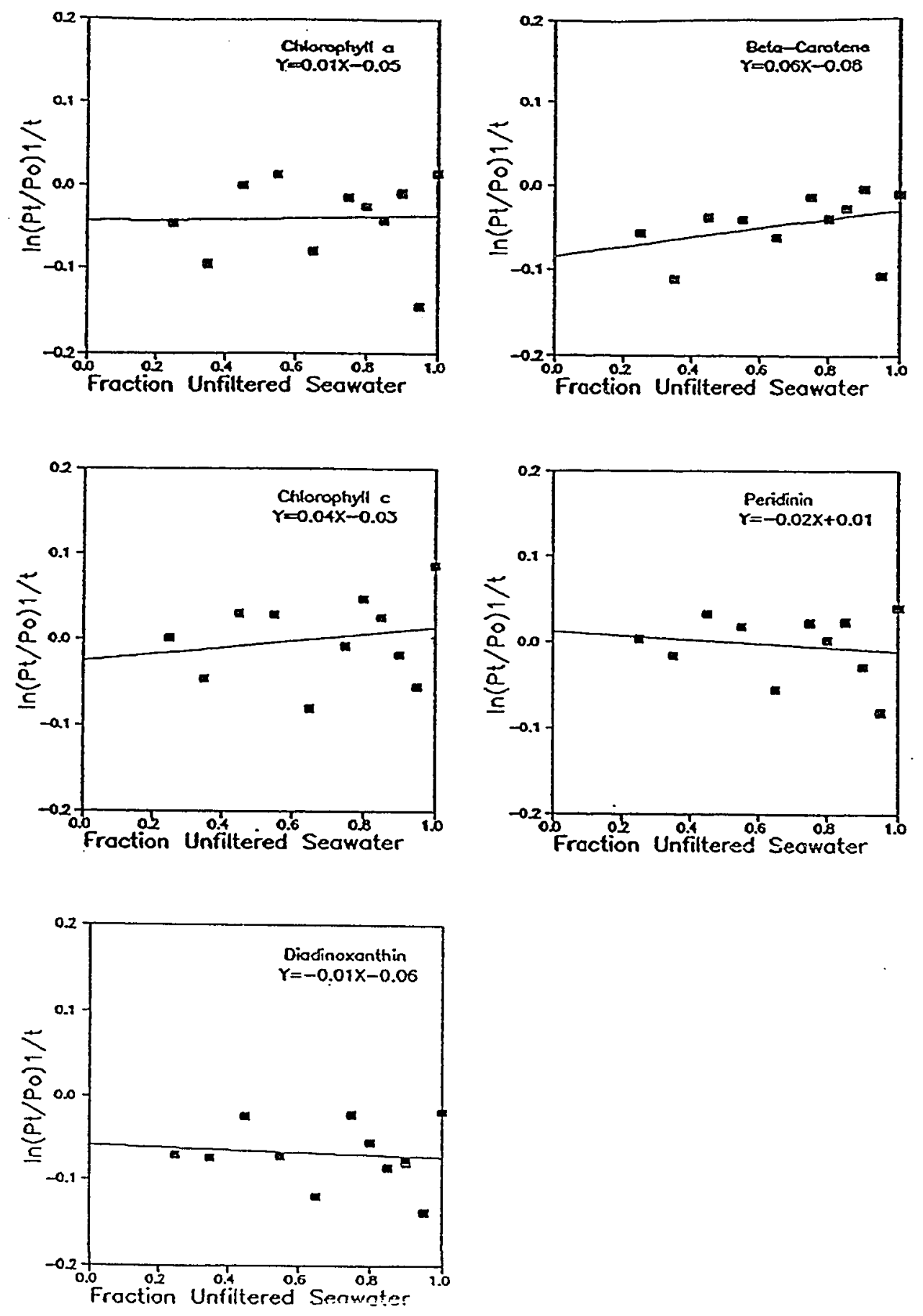

Figure 11. Dilution plots (net growth rate versus dilution factor) for pigments analyzed in experiment \#3 with Gymnodinium $\mathrm{sp}$. as the food source. Linear regression data are shown. 

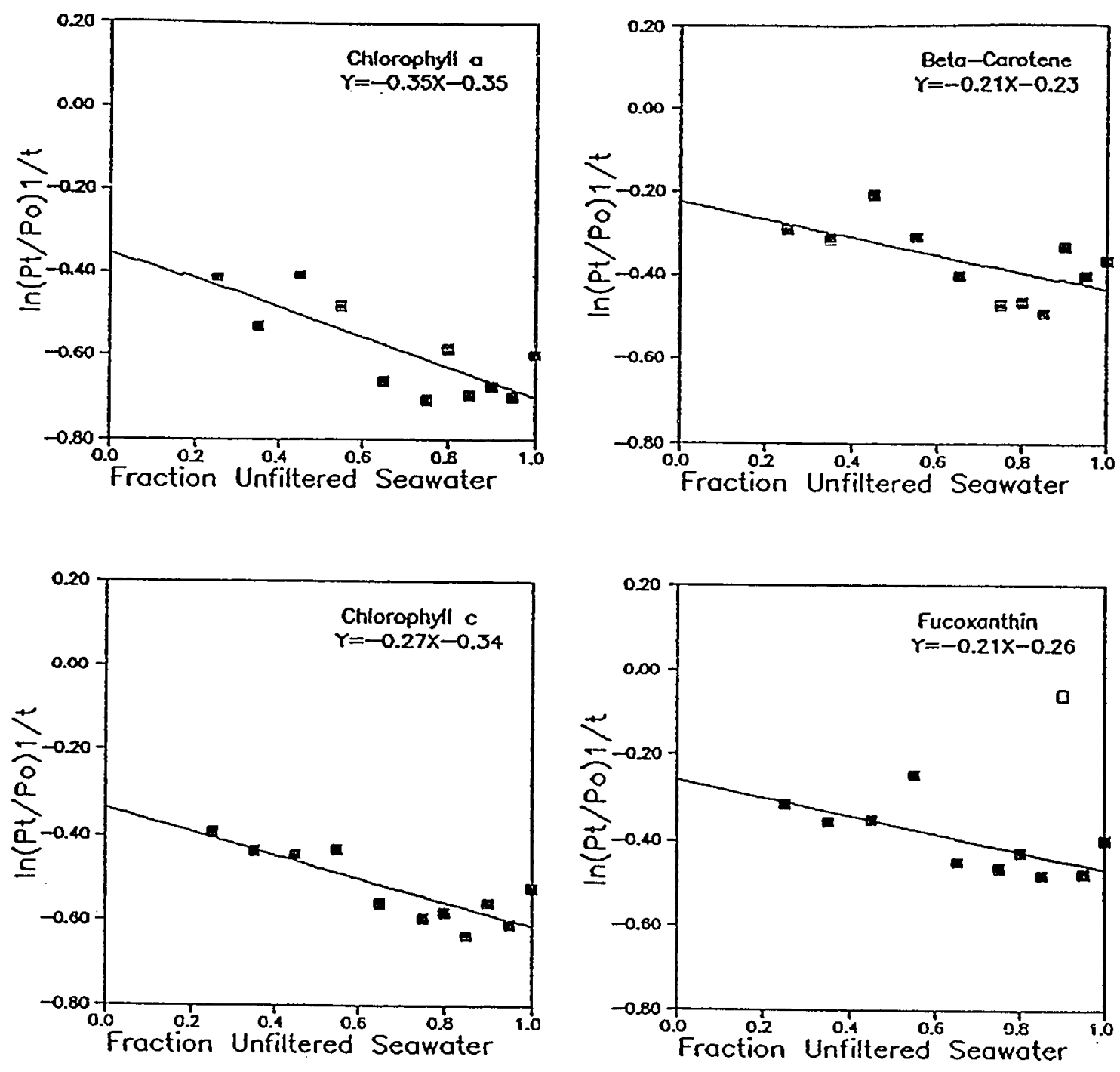

Figure 12. Dilution plots (net growth rate versus dilution factor) for pigments analyzed in experiment \#4 with Isochrysis galbana as the food source. Empty squares represent data points which were not included in the linear regression. Linear regression data are shown. 

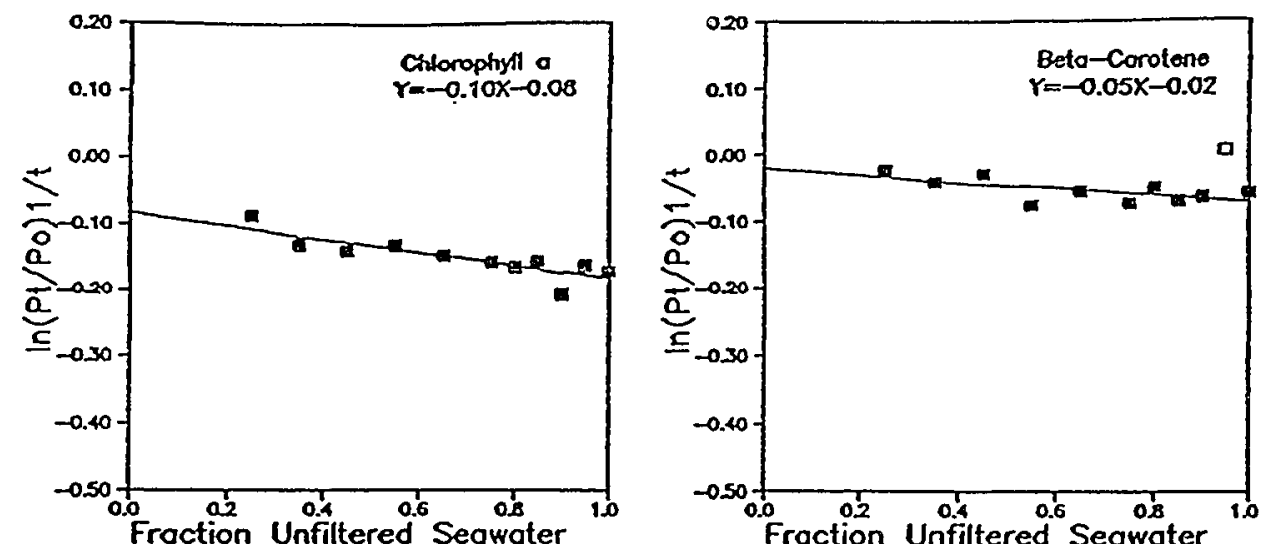

Fraction Unfiltered Seawater
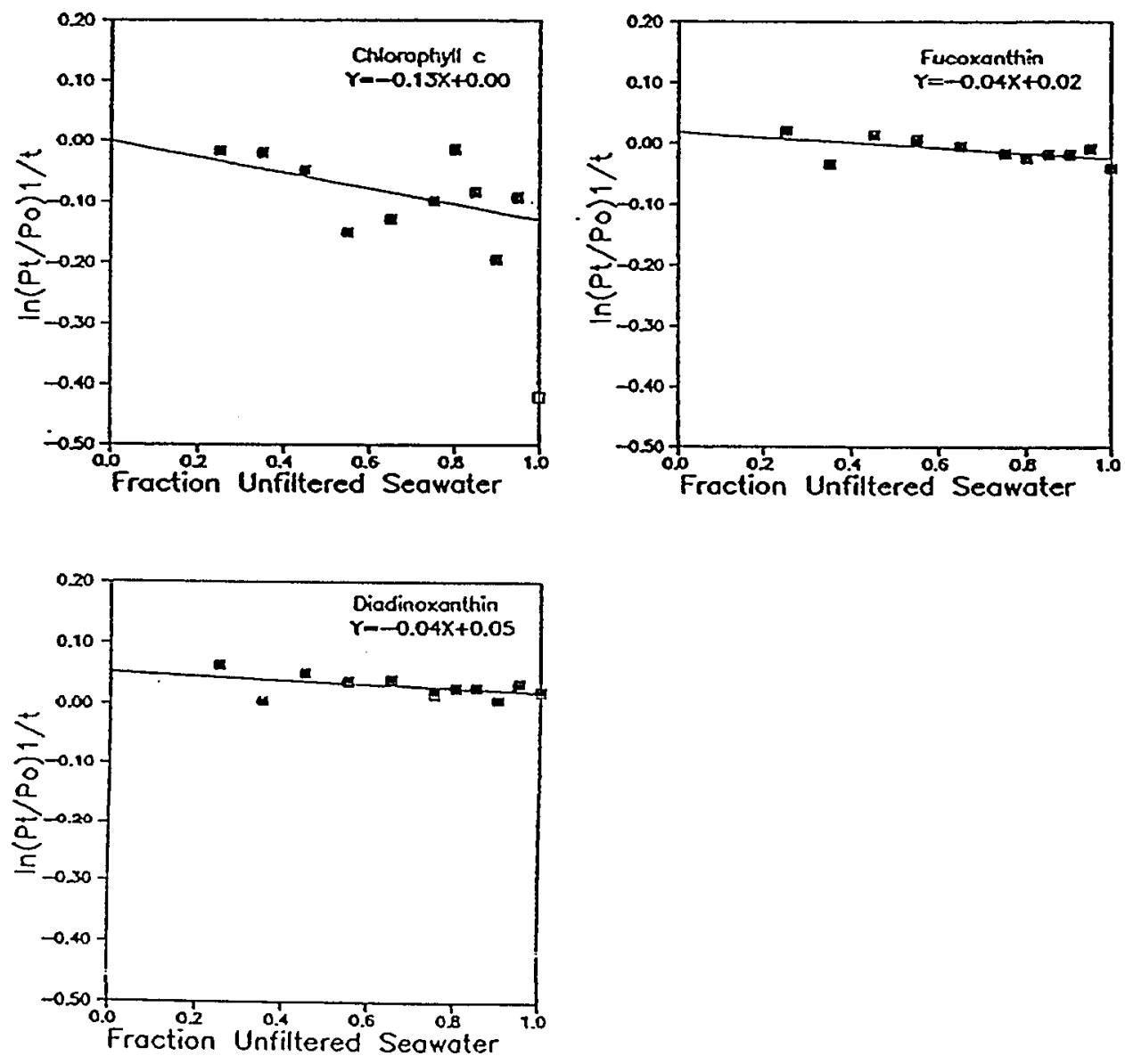

Figure 13. Dilution plots (net growth rate versus dilution factor) for pigments analyzed in experiment \#5 with Isochrysis galbana as the food source. Empty squares represent data points which were not included in the linear regression. Iinear regression data are shown. 

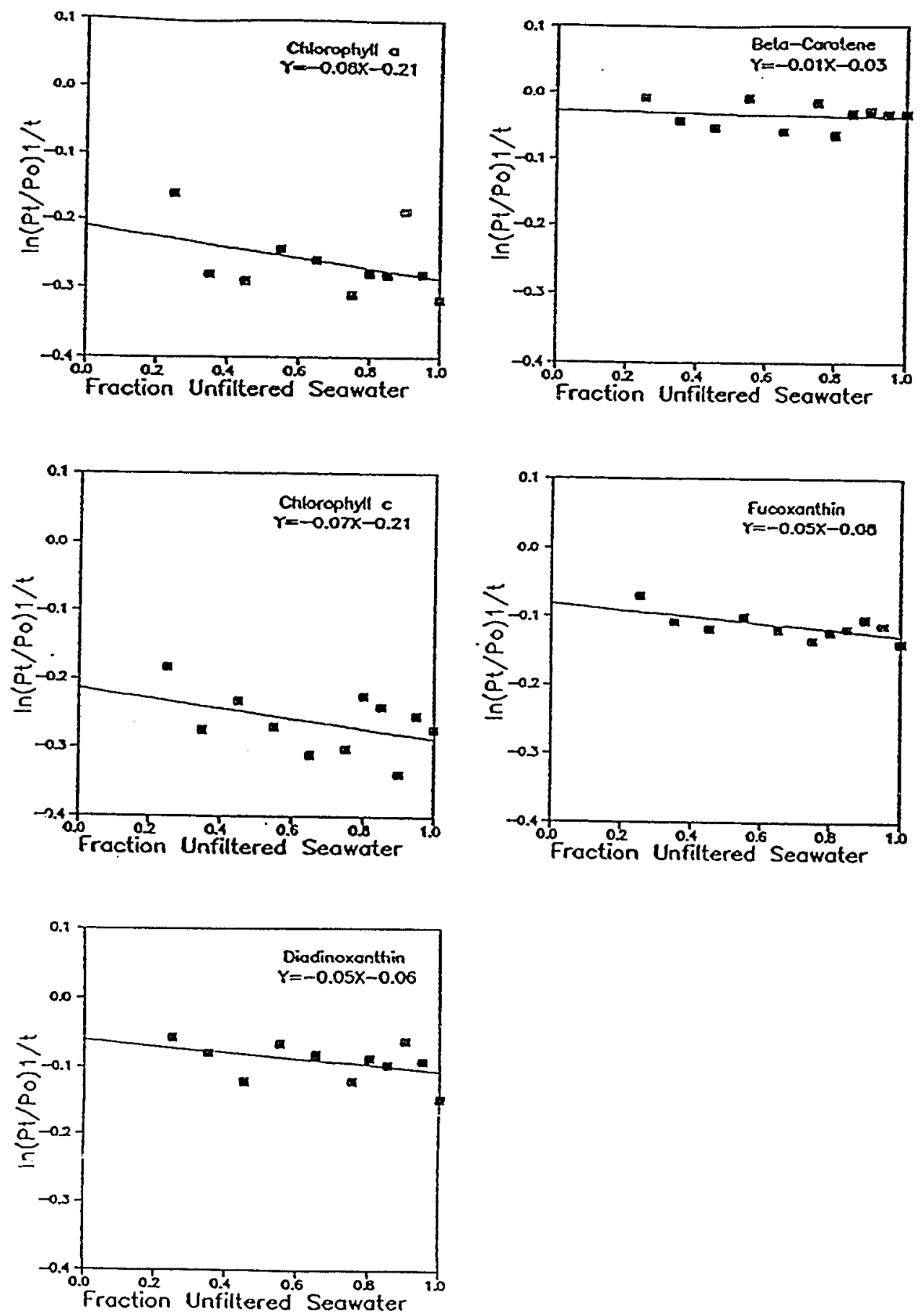

Figure 14. Dilution plots (net growth rate versus dilution factor) for pigments analyzed in experiment \#6 with Isochrysis galbana as the food source. Linear regression data are shown. 

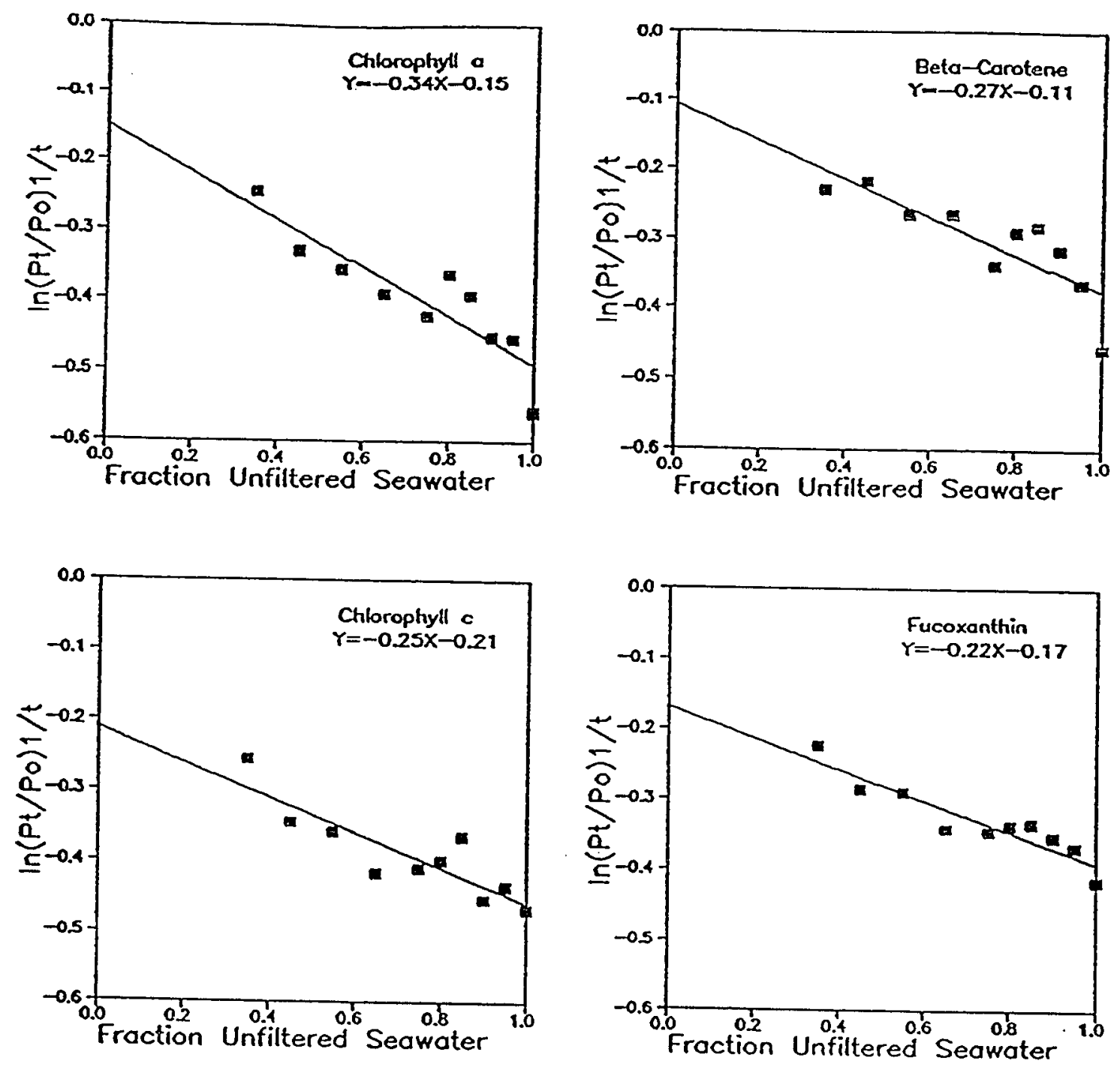

Figure 15. Dilution plots (net growth rate versus dilution fastor) for pigments analyzed in experiment \#7 with phaeodactylum tricornutum as the food source. Linear regression data are shown. 

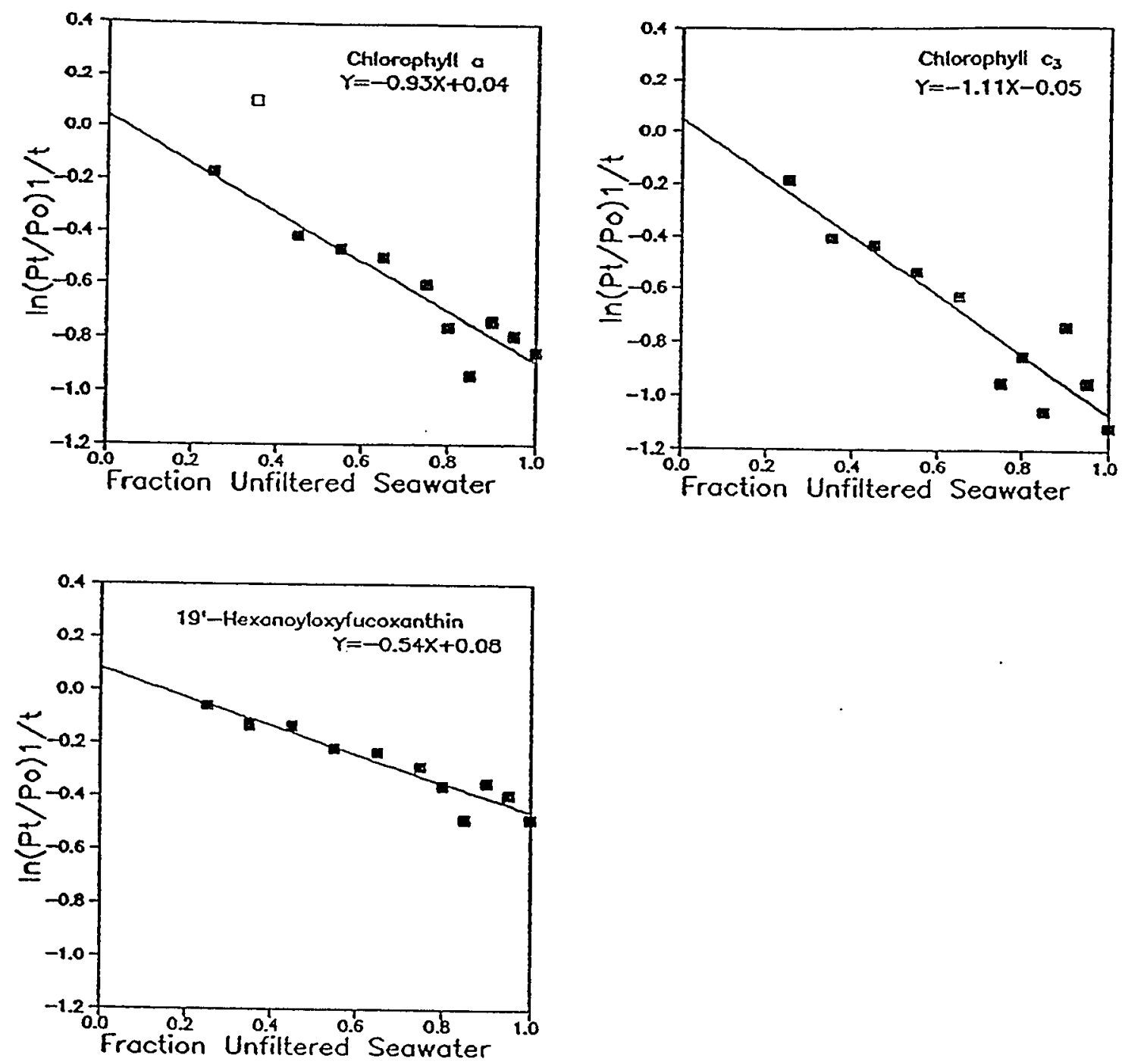

Figure 16. Dilution plots (net growth rate versus dilution factor) for pigments analyzed in experiment \#8 with Emiliania huxleyi as the food source. Empty squares represent data points which were not included in the linear regression. Linear regression data are shown. 

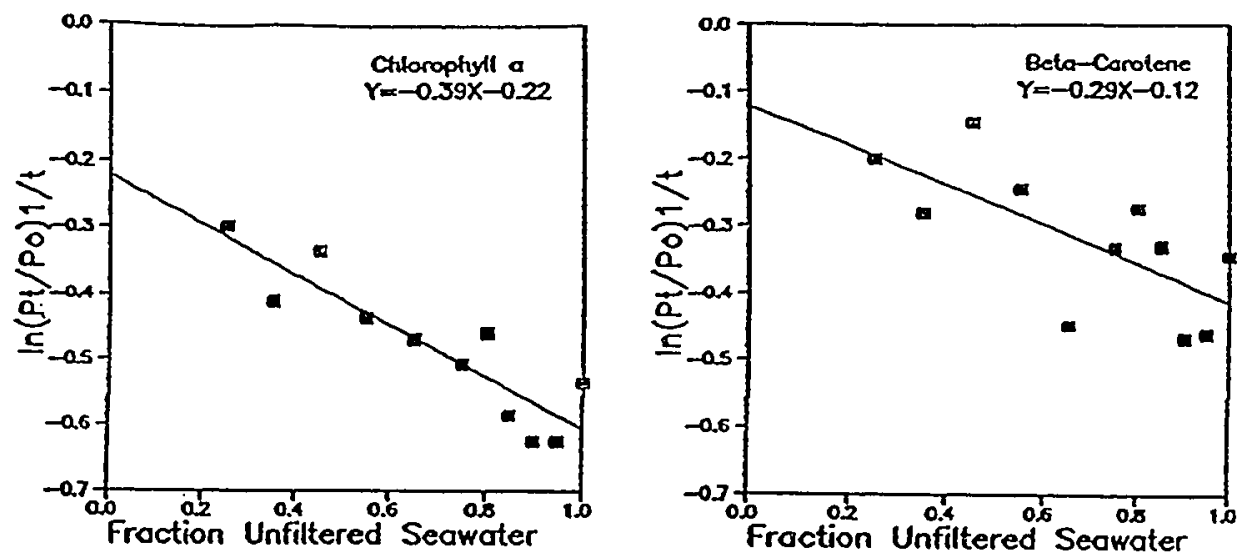

Fraction Unfiltered Seawater
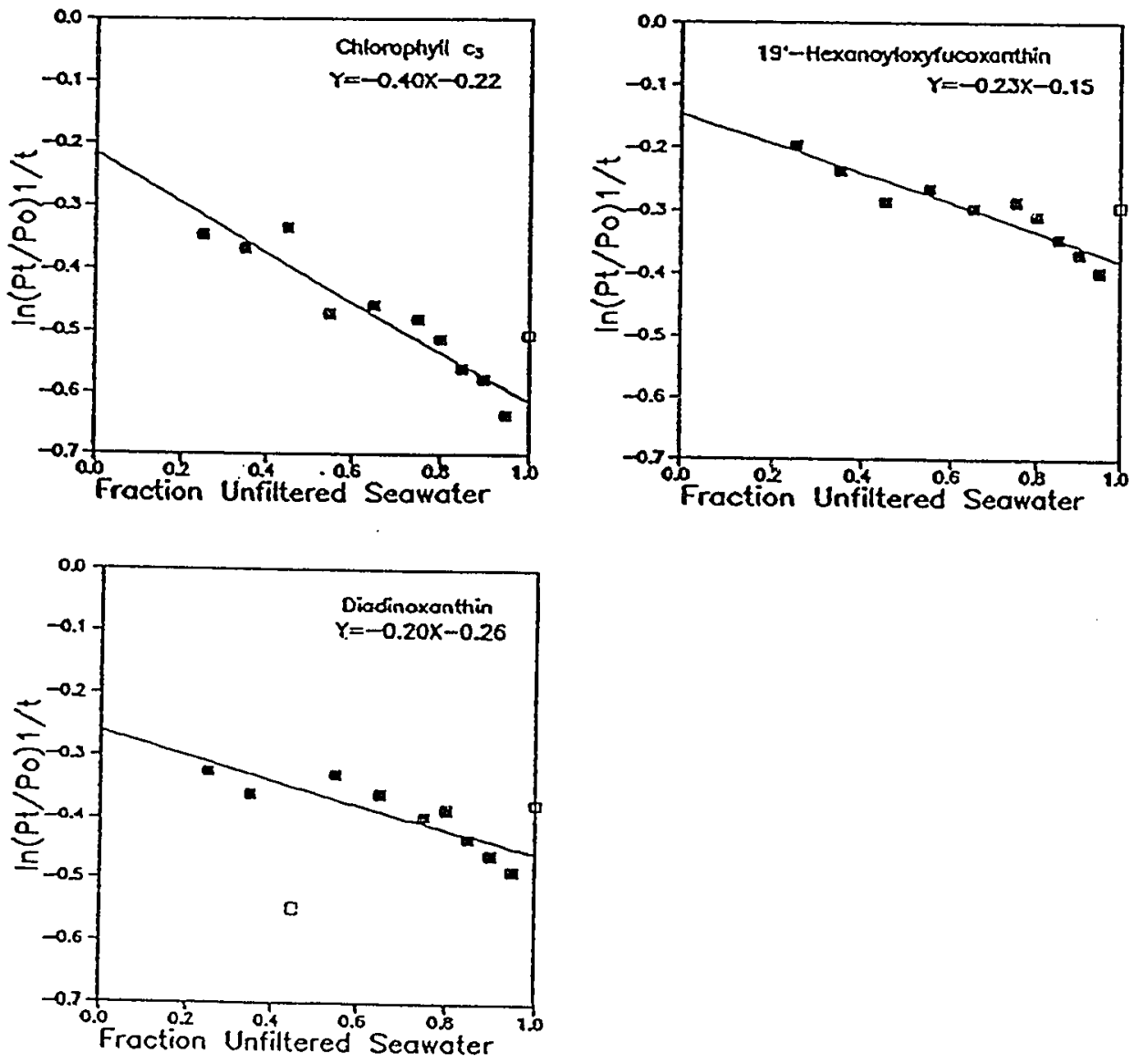

Figure 17. Dilution plots (net growth rate versus dilution factor) for pigments analyzed in experiment \#9 with Emiliania huxleyi as the food source. Empty squares represent data points which were not included in the linear regression. Linear regression data are shown. 

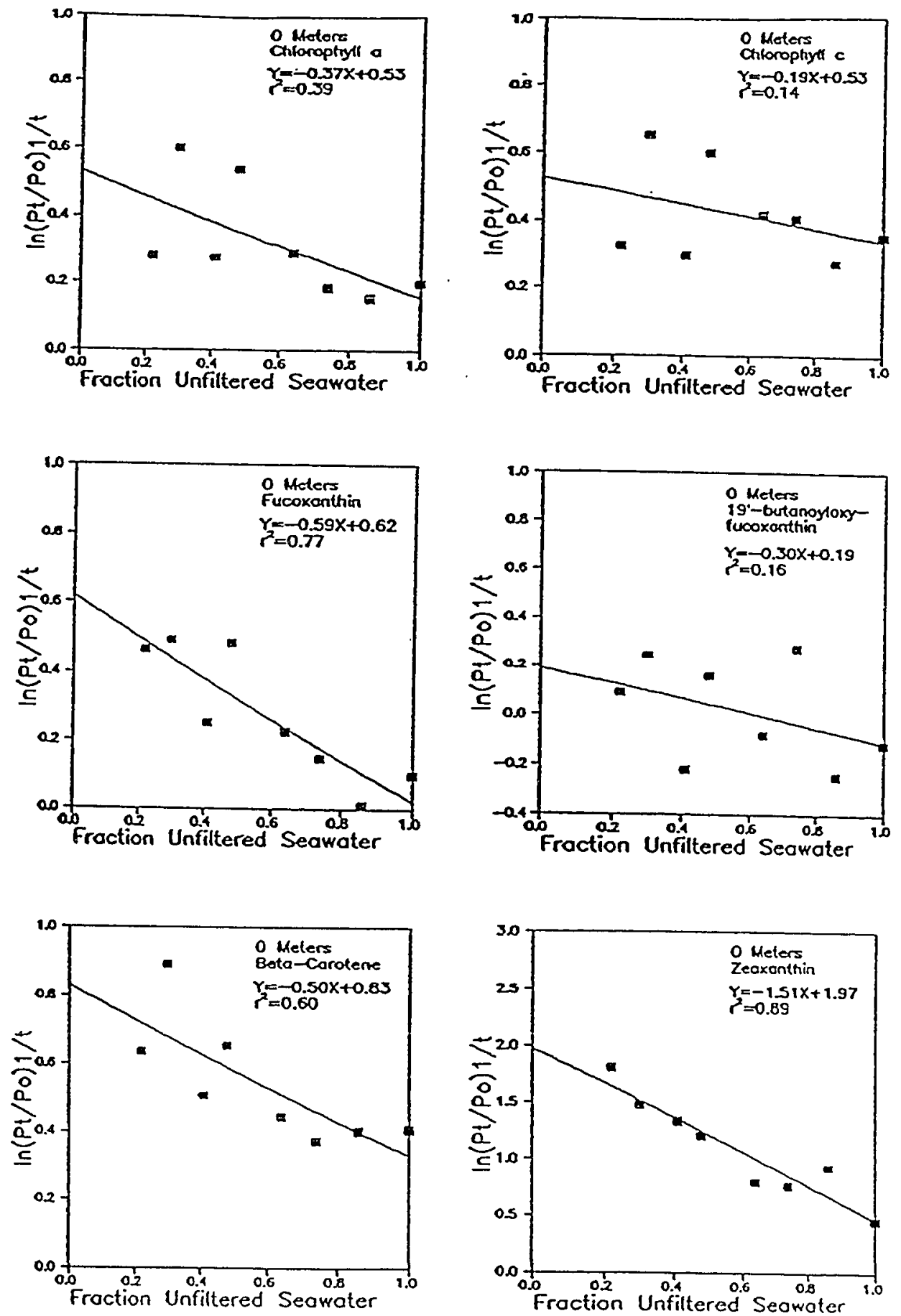

Figure 18. Dilution plots (net growth rate versus dilution factor) for pigments analyzed at 0 meters from Monterey Bay in September, 1991 , Linear regression data and coefficients of determination $\left(r^{2}\right)$ are shown. 

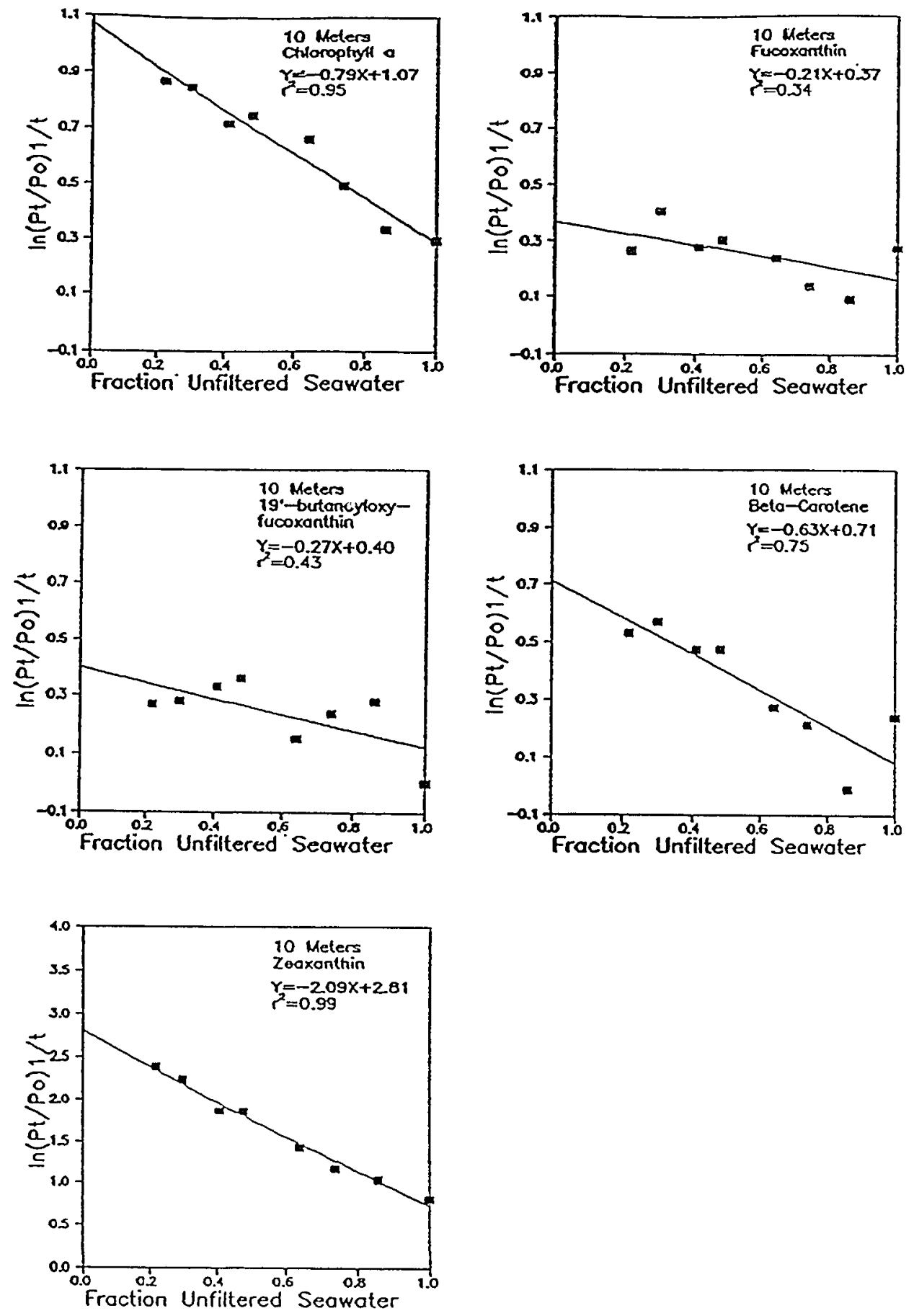

Figure 19. Dilution plots (net growth rate versus dilution factor) for pigments analyzed at 10 meters from Monterey Bay in September, 1991 inear regression data and coefficients of determination $\left(r^{2}\right)$ are shown. 

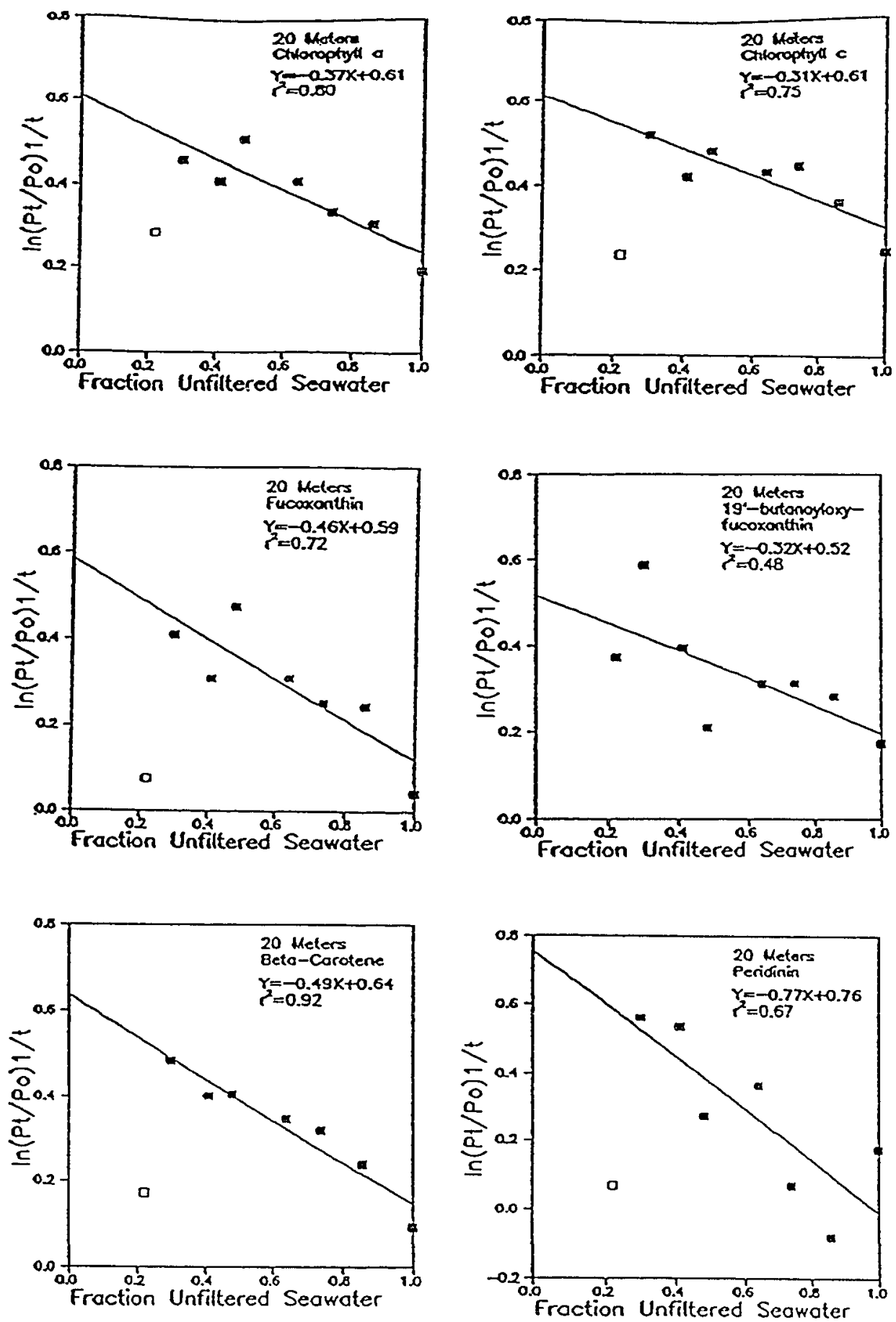

Figure 20. Dilution plots (net growth rate versus dilution factor) for pigments analyzed at 20 meters from Monterey Bay in September, 1991. Empty squares represent data which was not included in the linear regression. Linear regression data and coefficients of determination $\left(r^{2}\right)$ are shown. 

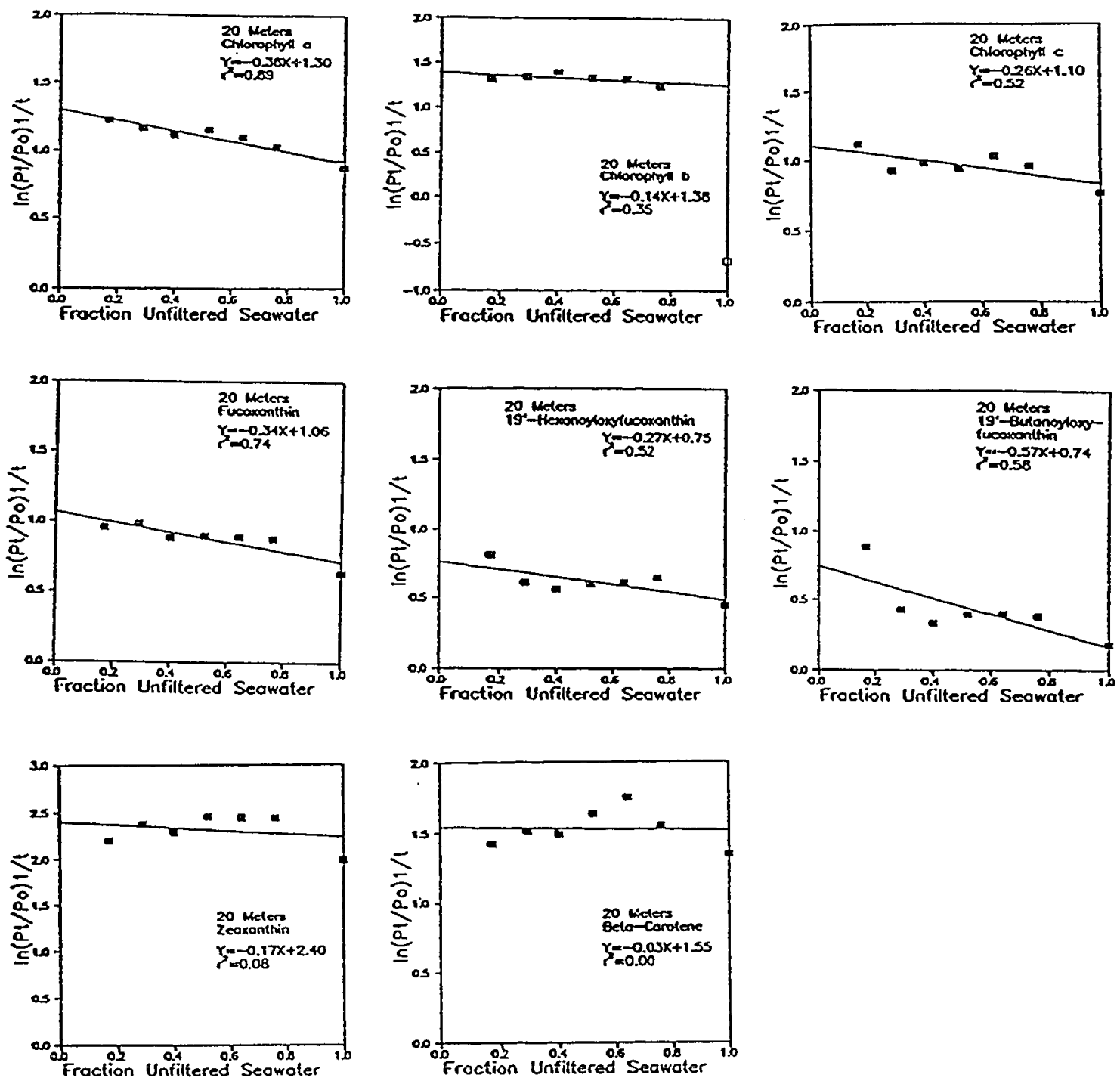

Figure 21. Dilution plots (net growth rate versus dilution factor) for pigments analyzed at 20 meters from Monterey Bay in March, 1992. Linear regression data and coefficients of determination $\left(x^{2}\right)$ are shown. 

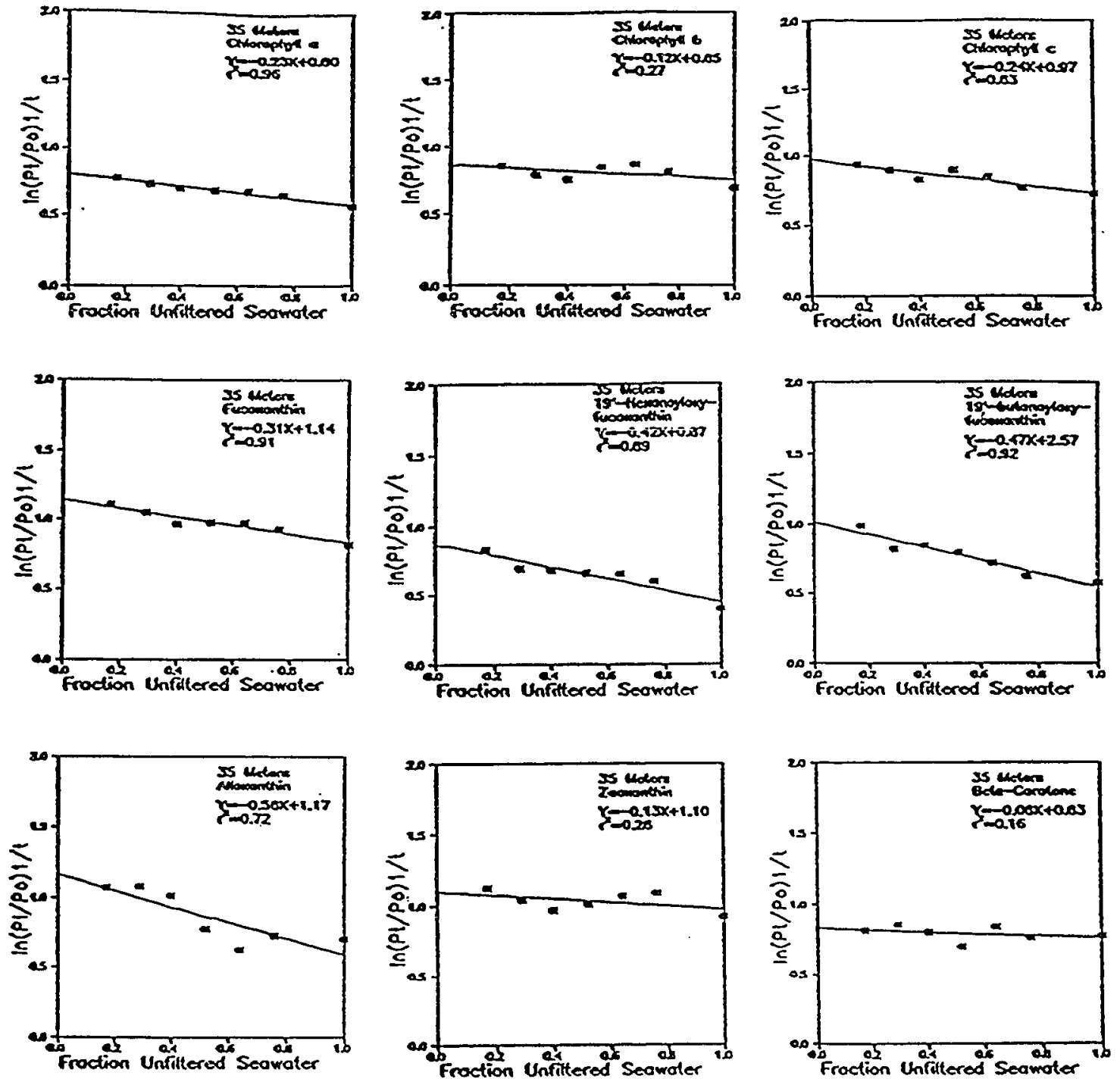

Figure 22. Dilution plots (net growth rate versus dilution factor) for pigments analyzed at 35 meters from Monterey Bay in March, 1992. Linear regression data and coefficients of determination $\left(r^{2}\right)$ are shown. 

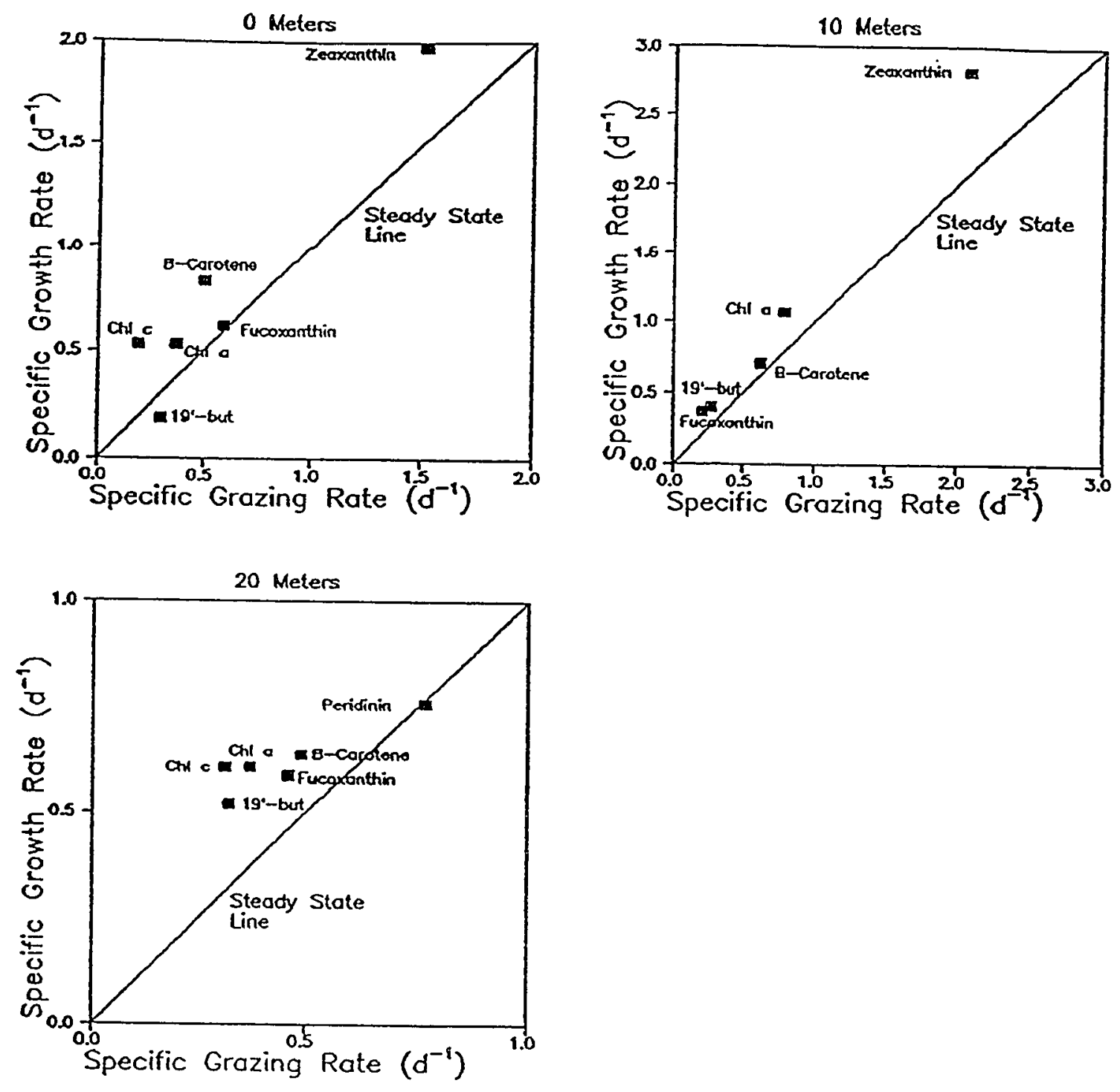

Figure 23. Growth rates versus Grazing rates for pigments analyzed in dilution experiments from Monterey Bay at 0,10 , and 20 meters in september, 1991. Solid line represents steady state where growth = grazing. 

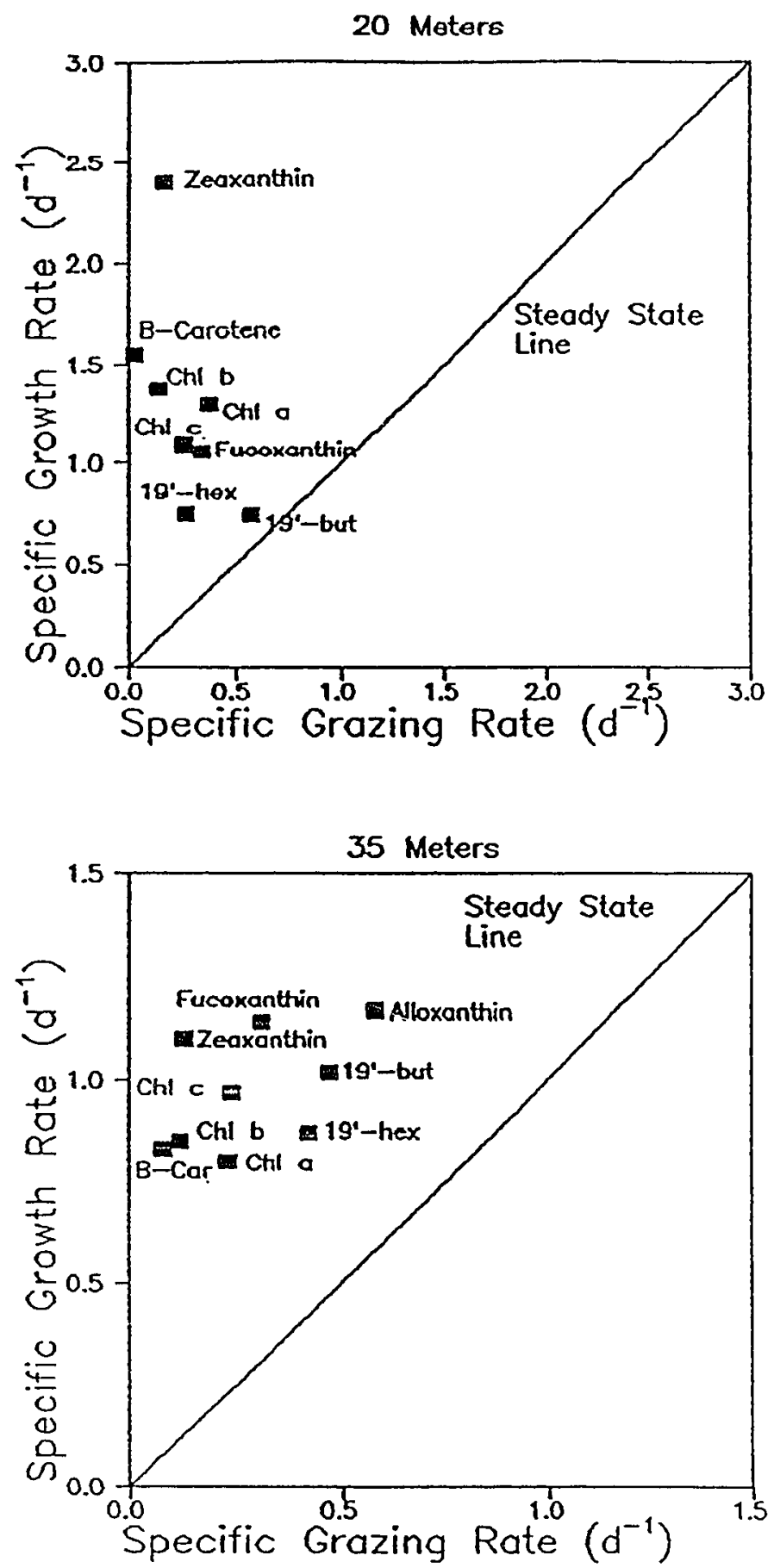

Figure 24. Growth rates versus Grazing rates for pigments analyzed in dilution experiments from Monterey Bay at 20 and 35 meters in March, 1992. Solid line represents steady state where growth $=$ grazing. 